\title{
AS IC\&T E O SECTOR PRODUTIVO EM PORTUGAL - - GÉNESE E DINÂMICAS DE COLABORAÇÃO
}

Teresa V. Oliveira

Novembro 2002

WP $\mathrm{n} \cong 2002 / 26$

DOCUMENTO DE TRABALHO

WORKI NG PAPER 
D I N Â M I A centro de estudos sobre a mudança socioeconómica

\section{AS I C\&T E O SECTOR PRODUTI VO EM PORTUGAL - - GÉNESE E di nÂMI CAS dE COLABORAÇÃo}

Teresa V. Oliveira

(teresa.v.oliveira@vizzavi.pt)

WP no 2002/ 26

Novembro de 2002

\section{Índice}

I NTRODUÇÃO

OBJ ECTIVO DO ESTUDO E METODOLOGI A DE INQUI RI ÇÃO 3

1. A insti tudionalização da C\&T em Portugal 4

2. A GÉNESE DAS IC\&T NO ÂMBITO DO QCA I

3. A INTEGRAÇÃo dAS IT E IC NUM MOdELO SI STÉMI CO DE GERAÇÃo dE COMPETÊNCI AS 7

4. A I NFLUÊNCIA DO ENSI NO SUPERI OR NA CONSTI TUI ÇÃO DAS I C\&T 13

5. A EVOLUÇÃo RECENTE DAS I C\&T

6. FINANCI AMENTO E I NVESTI MENTO TECNOLÓGI CO

7. A PROCURA POTENCI AL DAS I C\&T - DI MENSÃO E TI PO DE EMPRESAS 17

8. PROCESSOS DE PRODUÇÃO/ DI SSEMI NAÇÃO/ INTEGRAÇÃO dO CONHECIMENTO 19 
8.1. Estrutura interna e de RH

8.2. Gestão dos colaboradores $\quad \mathbf{2 1}$

8.3. A atracção/rotação dos recursos humanos $\quad \mathbf{2 4}$ $\begin{array}{ll}\text { 8.4. A formação de equipas de investigação - transdisciplinaridade e } & \\ \text { colaboração interna } & \mathbf{2 5} \\ \text { 8.5. Formas de gestão } & \mathbf{2 6}\end{array}$

$\begin{array}{ll}\text { 8.5. Formas de gestão } & \mathbf{2 6} \\ \text { 8.6 Cultura institucional } & \mathbf{2 8}\end{array}$

8.7. 0 acesso a fontes de conhecimento - as relações externas $\quad \mathbf{2 9}$

8.8 Como se avaliam $\quad \mathbf{3 0}$

8.9 Como disseminam o conhecimento $\quad \mathbf{3 0}$

8.10. Como estimulam a integração do conhecimento $\mathbf{3 2}$

9. QUE IMPACTOS ESTÃO A GERAR NAS EMPRESAS?

9.1. As relações entre empresas e centros de I\&D

9.2. Efeitos da actividade das IC\&T na capacidade competitiva e inovadora das empresas $\mathbf{2 6}$

10. A RELAÇÃO ENTRE I C\&T E EMPRESAS - LI MITAÇõES E CONDI ÇÕES DE SUPORTE

10.1 Tipo de solicitação científica e tecnológica $\quad \mathbf{4 2}$

10.2. Diferenciais na expectativas e necessidades institucionais $\quad \mathbf{4 4}$

11. QUE INFLUÊNCI A NA CONSI STÊNCI A DO SNI ?

11.1. A complementaridade das IC\&T numa rede científica e tecnológica nacional -
uma expectativa adiada

11.2. Desnivelamento das plataformas do conhecimento de base - investigação
centrada no país ou com perfil internacional?

11.3. A avaliação externa como forma de correcção de trajectórias $\mathbf{5 3}$

12. A GÉNESE DAS IC\&T COMO LIMITE PARA A CONSISTÊNCI A DO SNI - ALGUMAS
NOTAS CONCLUSIVAS

REFERÊNCI AS BI BLI OGRÁFICAS $\quad 65$ 


\section{NTRODUÇÃO}

Os programas PEDIP e CIENCIA estiveram na origem de um conjunto de Instituições de I\&D e de Transferência de Tecnologia (aqui designadas por Infra-estruturas Científicas e Tecnológicas IC\&T), que assumiram como objectivo melhorar o tipo de competitividade da indústria portuguesa e permitir um padrão de especialização tecnologicamente mais sofisticado.

Passada cerca de uma década após a constituição das IC\&T, procurou-se identificar quais os impactos socio-económicos da sua actividade. O presente texto apresenta as conclusões obtidas quanto ao tipo de interacções que se estabelecem entre IC\&T e o sector empresarial, considerando-se que a correcção das desarticulações ainda encontradas será em grande medida possibilitada pela concepção de modelos de avaliação integradores.

Após se proceder a uma breve apresentação do modelo de análise (sistémico) de funcionamento destas instituições, dão-se conta dos traços mais evidentes da génese das IC\&T, das características da envolvente em que operam e das configurações organizacionais encontradas.

Com base nos resultados de entrevistas realizadas em IC\&T e em empresas, e nos resultados de um inquérito por questionário a uma amostra representativa da indústria portuguesa, apresentam-se igualmente as conclusões sobre os efeitos que estas instituições estão a assumir na configuração de um Sistema Nacional de Inovação e geração de competências, e os constrangimentos que se colocam ao aproveitamento das capacidades científicas e tecnológicas existentes no país. 


\section{OBJ ECTI VO DO ESTUDO E METODOLOGI A DE I NQUI RI ÇÃO}

O presente trabalho apresenta algumas conclusões preliminares de um estudo sobre a interacção das instituições de I\&D com o sector produtivo.

As instituições de I\&D consideradas neste trabalho são de dois tipos: os grandes institutos de investigação criados no âmbito do programa CIENCIA (IC) e as infra-estruturas tecnológicas (IT) financiadas no âmbito dos programas PEDIP (que incluem Institutos de Novas Tecnologias - INT, Centros de Transferência de Tecnologia - CTT e Centros Tecnológicos - CT).

A recolha dos dados aqui apresentados foi efectuada através de um inquérito por questionário realizado a empresas da indústria transformadora portuguesa com mais de 10 trabalhadores, localizadas nas áreas metropolitanas de Lisboa e Porto. ${ }^{1}$

Posteriormente foram realizadas entrevistas semi-directivas em IC\&T, em empresas e a colaboradores de alguns organismos da administração central e local (listagem das instituições e pessoas inquiridas em anexo).

Foram contactadas a totalidade das IC\&T financiadas no âmbito dos dois programas, tendo sido solicitado uma entrevista aos responsáveis pela sua gestão/direcção e, caso existisse, à pessoa responsável pelos contactos com empresas.

As empresas a inquirir foram seleccionadas com base em listagens relativas à participação empresarial portuguesa em projectos BRITE-Euram e em projectos Eureka. Foi contactada uma amostra de empresas em função da sua localização e sector de actividade, tendo sido solicitadas entrevistas ao responsável pela gestão da empresa e ao responsável pelo contacto com as instituições de I\&D. Algumas empresas foram contactadas na sequência das entrevistas realizadas em IC\&T.

\footnotetext{
${ }^{1}$ As empresas eram as constantes da base BELEM de 1998 do INE, sendo a população alvo constituída por 2400 empresas na área metropolitana de Lisboa (AML) e 2647 na área metropolitana do Porto (AMP). O inquérito foi aplicado a uma amostra estratificada de acordo com as variáveis área metropolitana, sector de actividade (com desagregação a 3 dígitos), e dimensão da empresa. Obtiveram-se 824 respostas, sendo 421 da AML e 403 da AMP. A amostra ficou reduzida a 687 empresas, pelo facto de 133 respostas corresponderem a empresas em situação de cessação/inactividade e quatro empresas serem outliers (Ver M. Hill; A. Hill)
} 


\section{A institucionalização da C\&T em PORTUgal}

O sistema científico e tecnológico (SCT) português tem um passado que se pode considerar bastante recente, o que contribui para explicar a desarticulação verificada entre os seus vários agentes e a especificidade do perfil de actividades de I\&D actualmente desenvolvidas.

Considerando o desenvolvimento orgânico das instituições vocacionadas para a gestão da C\&T, podemos afirmar que o esforço de delineação de políticas científicas e tecnológicas em Portugal tem pouco mais de três décadas (com a constituição da JNICT) e que o investimento nas condições necessárias à realização de actividades de I\&D de nível internacional não tem muito mais de uma década, por via da adesão de Portugal à então Comunidade Económica Europeia.

Durante o Estado Novo as actividades científicas e tecnológicas foram desenvolvidas essencialmente pelos Laboratórios de Estado, vocacionados para o melhoramento dos vários sectores económicos através da realização de investigação aplicada e do desenvolvimento experimental. A investigação universitária, pelos riscos de independência e liberdade de reflexão que tinha subjacentes, nunca foi valorizada. Não se verificou qualquer política de forte investimento em I\&D como forma de recuperar um país atrasado

O estabelecimento de orientações para a C\&T apenas se começou a esboçar no decurso da década de 60 (Caraça, 1999), como resultado da existência de pressões e de apoios estrangeiros para o desenvolvimento de actividades científicas. Foi nesta década que se começou a promover investigação fundamental e aplicada, através de programas financiados pela NATO e pela OCDE (Ruivo, 1998).

A fundação da JNICT (Junta Nacional de Investigação Científica e Tecnológica) em 1967, considerada um marco histórico da política científica e tecnológica em Portugal, resultou da necessidade de estruturar as relações e contactos estabelecidos a nível internacional e de planear, coordenar e promover as actividades realizadas a nível nacional (Ruivo, 1998). Na constituição da JNICT esteve subjacente uma visão linear da actividade científica, atribuindo-se especial ênfase à investigação fundamental, sem que se estabelecessem quaisquer orientações no sentido da ligação entre produtores de saber e seus potenciais utilizadores (Ruivo, 1998).

A JNICT é reestruturada em 1988, com vista a permitir a sua actividade como agência de financiamento. Enquanto organismo técnico de apoio ao governo, tutelada pelo Ministério do 
Planeamento e Administração do Território, esta instituição assumiu como missão a "coordenação, programação e intervenção, em articulação com as políticas sectoriais, na área da ciência e da tecnologia."

Durante a década de 80 o Ministério da Indústria e Energia começou a procurar dar visibilidade ao "seu” laboratório nacional (o então LNETI) e a estimular o protagonismo desta instituição em termos tecnológicos (Caraça, 1999).

O início da década de 80 encontra-se marcado pela elaboração do Plano de Desenvolvimento Tecnológico da Indústria Transformadora Portuguesa (desenvolvido pelo LNETI em colaboração com o Center for Policy Alternatives do Massachussets Institute of Technology). Este Plano tinha como objectivo ajudar a definir a política industrial, tendo a ciência e a tecnologia sido consideradas decisivas para a melhoria da produtividade interna e competitividade externa. Embora este Plano não chegasse a ser implementado no âmbito da sua própria lógica, foi determinante para os pressupostos que presidiram ao financiamento das infra-estruturas tecnológicas no âmbito dos programas PEDIP.

A existência de dois interlocutores relevantes para a definição da política científica e tecnológica e tutelados por diferentes ministérios, a JNICT e o LNETI, veio a reflectir-se na "autonomização" dos mais marcantes programas para a C\&T do QCA I: os programas PEDIP (Programa Específico para o Desenvolvimento da Indústria Portuguesa - 1988/1992) e CIENCIA (Criação de Infra-estruturas Nacionais de Ciência, Investigação e Desenvolvimento - 1990/1993). Embora existissem objectivos comuns a ambos os programas, estes foram estabelecidos no quadro de uma lógica linear, que visava a “mera” criação de competências científicas e tecnológicas, sem salvaguardar a articulação entre agentes.

\section{A GÉNESE DAS I C\&T NO ÂMBITO DO QCA I}

A urgência do investimento em infra-estruturas de carácter científico e tecnológico realizado no final dos anos 80, era visível pelas deficiências estruturais do país em termos de actividades C\&T.

Os programas então aprovados intervieram em domínios como a criação de infra-estruturas, a formação avançada de recursos humanos, a criação de instituições e mecanismos de apoio à inovação e o apoio a projectos de I\&D. Foram objectivos fundamentais do QCA I o reforço da capacidade nacional em C\&T, como forma de diversificar e desenvolver tecnologias emergentes, reduzir as 
disparidades regionais, desenvolver massas críticas, e suportar a inovação industrial através da cooperação entre instituições de I\&D e empresas.

O programa CIENCIA visava estabelecer as bases para o desenvolvimento científico e tecnológico do país através do reforço do potencial de C\&T, do aperfeiçoamento da estrutura do SCT, e da diminuição das assimetrias regionais. Este programa assumia-se com uma lógica pré-competitiva, tendo a ideia implícita de apoiar actividades de I\&D em determinadas direcções estratégicas, congruentes com a configuração do novo paradigma tecnológico.

A formação avançada de recursos humanos constituiu uma linha de intervenção prioritária no âmbito do CIENCIA. O programa procurou também ultrapassar as carências de infra-estruturas no País através da criação de novos centros e institutos, e através da modernização e reforço de laboratórios e centros de investigação existentes. Foram constituídos 12 institutos de investigação formados por equipas universitárias (de grande ou média dimensão), e criados ou reforçados outros 35 centros de investigação, pequenas unidades de investigação básica e pré-competitiva.

Os grandes institutos, que ficaram conhecidos como "Institutos do CIENCIA" (IC), foram pensados para se configurarem com uma dimensão significativa (desejavelmente com mais de um pólo), por forma a criar massas críticas estabelecidas em rede (em média com um total de 200 investigadores). Os outros centros congregavam um número reduzido de investigadores (em média 30 a 50 investigadores).

Nos objectivos do programa PEDIP incluíam-se a "reestruturação das indústrias tradicionais; a intensificação tecnológica das produções industriais; a criação de novos produtos com base em novas tecnologias; a melhoria da produtividade e reforço da qualidade; o aproveitamento racional dos recursos nacionais; o enriquecimento dos recursos humanos no âmbito tecnológico”.

O PEDIP procurou fortalecer algumas infra-estruturas tecnológicas (IT) lançadas já na sequência do Plano de Desenvolvimento Tecnológico da Indústria Transformadora Portuguesa, paralelamente à criação de um conjunto de novas instituições. As infra-estruturas estimuladas no âmbito deste programa deveriam permitir o estabelecimento de actividades em rede e complementar as funções dos vários agentes do sistema.

Foram constituídos vários tipos de IT, complementares quanto aos seus objectivos: Laboratórios de Metrologia, Centros Tecnológicos, Institutos de Novas Tecnologias, Centros de Excelência, Centros 
de Transferência de Tecnologia, Unidades de Demonstração, Centros de Incubação e Pólos Tecnológicos.

Passada cerca de uma década após a constituição dos IC e das IT, a questão que se coloca é: qual a influência que estas instituições estão a assumir na consolidação do SCT e em que medida estão a permitir a emergência de um Sistema Nacional de Inovação (SNI)?

\section{A INTEGRAÇÃo dAS IT E IC NUM MOdELO SISTÉMICO DE GERAÇÃO DE COMPETÊNCI AS}

A maior parte das instituições criadas no âmbito do programa PEDIP e CIENCIA foi pensada de forma autónoma, o que se reflecte na escassa cooperação entre elas evidenciada.

Tal desarticulação afigura-se especialmente negativa dado que, mais do que a criação de conhecimento científico e tecnológico, é a capacidade de articular esse conhecimento num quadro global de geração de competências que está na génese dos sistemas nacionais de inovação(Lundvall, 1992; Lundvall, Johnson, Andersen e Dalum, 2001).

Como atesta o paradoxo europeu (Soete, 2000), o mero investimento em I\&D não explica o desenvolvimento dos países. É a capacidade de sustentar processos colectivos de aprendizagem e de articular os recursos existentes (Kim, Nelson, 2000), que explicam as dinâmicas de desenvolvimento registadas nas últimas décadas em alguns países desenvolvidos (Soete, 2000) e de desenvolvimento intermédio (Kim, Nelson, 2000).

A sedimentação de um SNI está associada à qualidade dos processos de produção de conhecimento promovidos individual e colectivamente, mas também à capacidade de os integrar num quadro mais vasto de utilização desse conhecimento, permitindo a criação de valências tecnológicas. Daí que a qualidade das relações que os agentes do SCT estabelecem entre si seja determinante para a amplitude das competências geradas num determinado país.

A geração de competências científicas e tecnológicas decorre de processos de interacção formais e informais, estabelecidos entre instituições e agentes envolvidos na utilização de uma base de conhecimento comum. Os processos de aprendizagem que permitem a criação de competências têm lugar num contexto socio-económico moldado pelos tipos de empresas e pelas suas solicitações científicas e tecnológicas, pelas políticas nacionais (e internacionais), pelas culturas individuais e 
colectivas, pelos níveis de conhecimento e pelas formas de aprendizagem colectiva, pelas formas de gestão do conhecimento, pelas instituições e burocracias de suporte à geração de conhecimento.

O carácter interdependente e complementar que se perspectiva para as instituições envolvidas na produção de conhecimento levou a que se optasse por uma designação comum para as instituições promovidas no âmbito dos dois programas: infra-estruturas científicas e tecnológicas (IC\&T). Definiram-se as IC\&T enquanto instituições com a missão de produzir, disseminar e promover a integração de conhecimento de carácter científico e tecnológico, sejam elas autónomas ou inseridas em universidades.

O conhecimento será entendido aqui como o conjunto organizado de informações, de carácter processual (saber como), cognitivo (saber o quê; saber porquê) e afectivo (saber quem $e$ saber evoluir $^{2}$ ), dotadas de sentido individual e colectivo, que sustentam a acção de indivíduos e grupos. Existe conhecimento quando a informação disponível pode ser descodificada e integrada com significado num todo coerente, quando os indivíduos são capazes de utilizar essa informação para responderem de forma concreta às solicitações do meio. Para ser adquirido o conhecimento pressupõe a existência de processos de aprendizagem formais ou informais, que podem ser suportados no quadro de actividades institucionais ou através de processos informais de interacção.

A aprendizagem decorre de um processo de inquirição face à envolvente, assente no pensamento e na aç̧ão para resolver incertezas. Há aprendizagem quando aumenta a capacidade de se assumir uma acção efectiva. A aprendizagem consiste no processo através do qual informação nova é associada à base de conhecimento existente, permitindo a aquisição de novas estruturas de comportamento e representações de objectos. Tal processo é suportado por esquemas mentais, estruturas cognitivas relativas a conceitos, entidades, eventos, usadas pelos indivíduos para codificar e representar a informação de forma eficiente.

Para que as IC\&T possam estar na origem da geração de competências individuais e colectivas é necessário que produzam conhecimento, mas também que disseminem esse conhecimento para os seus potenciais utilizadores, e que facilitem a sua integração em termos conceptuais e processuais.

O conhecimento produzido pode ter um carácter científico ou tecnológico, e supõe o recurso a fontes de informação externas as quais, em articulação com a base de conhecimento detida pela organização/indivíduo, permitirão a criação de novo conhecimento.

\footnotetext{
${ }^{2} \mathrm{O}$ saber evoluir constitui um elemento distintivo das competências individuais e organizacionais. O saber evoluir está
} 
A disseminação de conhecimento constitui o processo de partilha dos resultados alcançados individual e institucionalmente, sendo através dela que se processa parte da sua validação.

A integração do conhecimento associa-se ao processo de atribuição de significados à informação que se recebe. Para que a integração possa ter lugar é necessário que os indivíduos detenham as bases e recursos conceptuais que lhes permitam descodificar significados e conceitos, atribuir sentido a essa informação e mobilizá-la em contextos específicos.

Quer a disseminação quer a integração de conhecimento podem estar na origem de processos simultâneos de produção de novo conhecimento (para os receptores do processo), daí se considerar o carácter global e permanente da geração de conhecimento.

É a capacidade de mobilizar simultaneamente diversos tipos de conhecimento, dando resposta a problemas ou permitindo que se melhorem/desenvolvam novos processos e produtos, que define as competências científicas e tecnológicas. As competências serão assim conhecimento (de vários tipos) em acção.

A capacidade de gerar competências colectivas pressupõe que as instituições se posicionem entre si de forma complementar e sinérgica, facilitando os processos de produção, disseminação e integração do conhecimento.

A capacidade das IC\&T gerarem as competências que suportam os SNI decorre da qualidade das actividades desenvolvidas a cada um dos três níveis anteriormente referidos, mas também da qualidade das interacções estabelecidas entre eles. Não é porém “obrigatória” uma intervenção de cada IC\&T a todos os níveis. As instituições podem complementar-se através das actividades desenvolvidas por outras, por forma a cobrirem as três fases da geração de competências.

associado à adaptabilidade, à aceitação da "insuficiência do saber” e ao desenvolvimento do potencial. 


\section{Características da envolvente com influência}

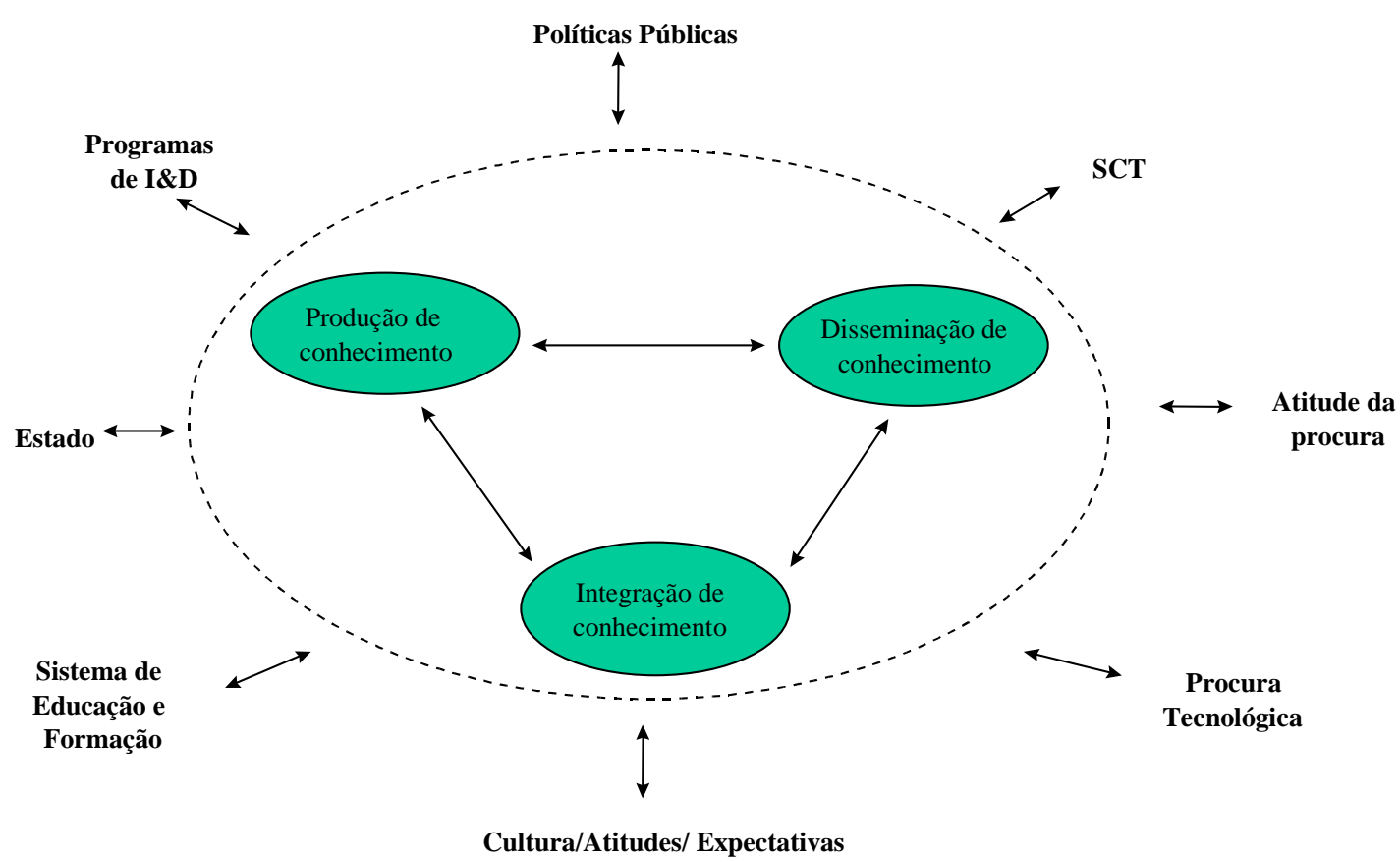

A actividade das IC\&T resulta da configuração de um conjunto de factores externos e internos.

A qualidade dos inputs e das interaç̧ões que estabelecem com o exterior são determinantes no sistema de geração de competências. Os recursos que influenciam a actividade desenvolvida pelas IC\&T são de dois tipos: características (inputs) associadas à envolvente e ao contexto socioeconómico em que estas se inserem, e inputs processuais, mobilizados de forma mais directa para sustentar processos de produção, disseminação e integração de conhecimento.

Também as configurações internas das IC\&T no que se refere à amplitude e qualidade dos recursos financeiros e humanos disponíveis, à qualidade da gestão e das configurações organizacionais, à capacidade de identificar e utilizar outras fontes de conhecimento, determinam a capacidade de transformar os inputs em resultados tangíveis e intangíveis.

O resultado das actividades das IC\&T regista-se a dois níveis:

1) os outcomes imediatos desses processos, expressos por exemplo em produtos, processos, constituição de novas organizações, geração de competências, disseminação do conhecimento; 
As IC\&T E O SECTOR PRODUtiVo EM PORTUGAL - GÉNESE E DINÂMICAS DE COLABORAÇÃo

2) os impactos, de carácter mais estrutural e de longo prazo, que se expressam na qualificação do sistema económico em termos científicos e tecnológicos e na densificação das relações entre agentes do SNI. 
Modelo sistémico de geração de competências das I C\&T

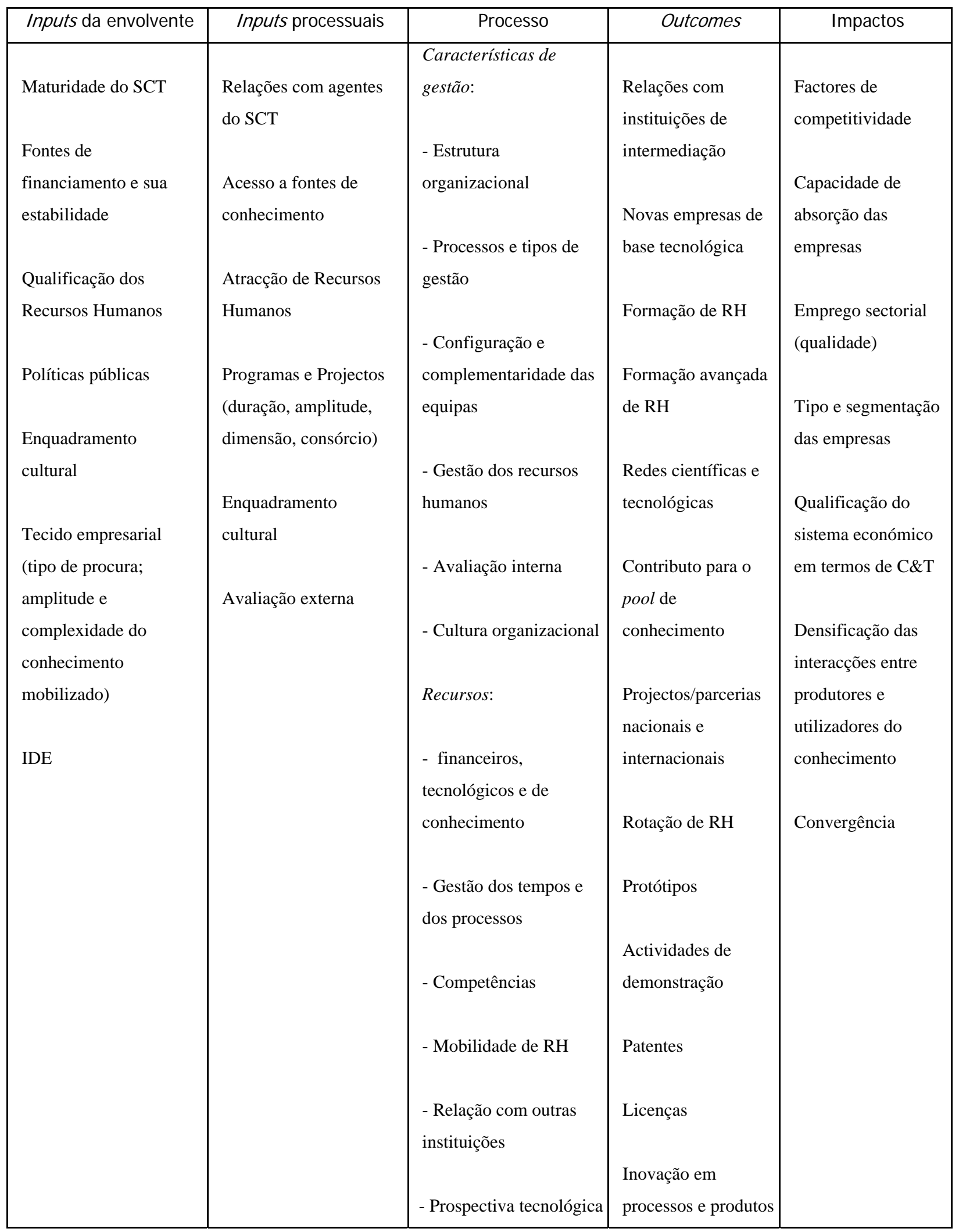




\section{A INFLUÊNCIA DO ENSINO SUPERIOR NA CONSTITUI ÇÃO DAS IC\&T}

O SCT está inevitavelmente associado à história e à evolução do ensino superior, também marcado pela sua juventude relativa e pelas vicissitudes da sociedade portuguesa no último quartel do século XX.

Em finais da década de 80 foi publicada legislação que estabelece a autonomia das universidades e a sua missão: as universidades são "centros de criação, transmissão e disseminação da cultura, da ciência e da tecnologia, que, através da articulação do estudo, da docência e da investigação, se integram na vida da sociedade”, tendo assegurada a sua autonomia estatutária, científica, pedagógica, administrativa, financeira e disciplinar.

Embora o Estado deva financiar o desenvolvimento de actividades de I\&D nas universidades, estas revelam uma situação de grande penúria financeira a este nível.

No início dos anos 90 assistiu-se à criação de um conjunto de IPSFL no seio das universidades, com o objectivo de aproveitar os fundos do QCA I e de permitir maior flexibilidade na gestão das verbas provenientes dos programas europeus de C\&T. As universidades não apresentavam condições suficientes para que se pudessem realizar as actividades de investigação inerentes ao cumprimento da sua missão, quer por questões relacionadas com a escassez de meios financeiros, quer por constrangimentos decorrentes da burocracia universitária, que constituíam um sério entrave ao aproveitamento das oportunidades abertas pelos programas de investigação comunitários e às relações com o exterior. Algumas IPSFL, estimuladas no âmbito do PEDIP e do CIENCIA por departamentos ou por grupos de docentes, importaram os modelos de organização e gestão das universidades.

A escassez de recursos humanos qualificados que pudessem assegurar a constituição e manutenção das IC\&T fora dos quadros das universidades, a lógica linear que esteve subjacente à constituição destas instituições, paralelamente aos problemas decorrentes de um país onde as elites científicas são diminutas, por isso prestigiadas e com capacidade de influenciar as decisões políticas, levaram a que estas instituições fossem criadas sem uma visão integradora das suas complementaridades e responsabilidades várias, e nalguns casos permitindo a sua duplicação. 
Os IC encontram-se na sua maioria localizados em campus universitários, recorrendo a docentes para assumirem as funções de responsáveis de projectos e de laboratórios.

Quanto às IT, embora estas assumam uma vocação de interface com a indústria, a sua constituição foi, em bastantes casos, influenciada pelas necessidades da investigação universitária. Se os Centros Tecnológicos (CT) foram desenvolvidos com forte apoio empresarial e com objectivos bastantes "imediatos" (nomeadamente pelas exigências de normalização e de certificação que se iriam colocar na actividade exportadora), nos Institutos de Novas tecnologias (INT) e nos Centros de Transferência de Tecnologia (CTT) encontram-se realidades distintas: várias IT constituíram um meio de docentes universitários obterem meios para investigar.

\section{A eVOLUÇÃo RECENTE dAS I C\&T}

Nalguns casos as IT resultaram da mobilização de agentes, noutros de convites. O financiamento das instituições foi realizado com pendor marcadamente liberal, esperando-se que fosse o mercado o responsável pela triagem das instituições de sucesso. Esta realidade estimulou uma lógica de aprovação de instituições de forma "equilibrada” em termos geográficos e institucionais, nem sempre congruente com as necessidades e capacidades evidenciadas localmente.

O facto da constituição destas instituições ter sido realizada por grupos e personalidades prestigiadas, e o peso que os lobbies empresariais e académicos tiveram junto do poder político, dificultaram a capacidade dos técnicos redimensionarem os apoios solicitados.

A evolução das IC\&T tem reflectido várias necessidades de ajustamento institucional, resultantes quer de novas exigências de funcionamento e organização destas instituições, quer da compreensão dos pressupostos desajustados que estiveram na sua origem.

As alterações organizativas que se têm registado nos IC decorrem essencialmente da necessidade de gerar coerência interna entre as várias áreas, e de alterar a configuração inicial dos pólos, marcada pela heterogeneidade de interesses de investigação. Como o financiamento era determinado pelo número de doutorados, a agregação destes investigadores foi a grande motivação destas organizações. 
As alterações registadas a nível das IT verificam-se essencialmente a dois níveis: alterações nos mecanismos de gestão e condução das instituições (expressando necessidades de melhoria do posicionamento estratégico da instituição e de acréscimo da flexibilidade na sua gestão), e alterações a nível das actividades desenvolvidas (quer no seu alargamento, quer na redefinição das formas de relacionamento com instituições de I\&D e empresas).

Apesar das IT não terem como vocação inicial realizar investigação de cariz universitário, o enquadramento de muitas delas é claramente universitário e frequentemente as actividades realizadas respondem a necessidades dos docentes. Contudo, não se denota que exista uma articulação entre as perspectivas de evolução das IT e das universidades às quais se encontram interligadas. A opção por uma ligação mais estreita entre instituições parece resultar mais da opção política das IT do que de uma verdadeira lógica de complementaridade entre instituições.

\section{FINANCI AMENTO E I NVESTI MENTO TECNOLÓGI CO}

O financiamento externo das IC\&T revela-se fulcral para a sobrevivência da maior parte destas instituições. No caso dos IC esta dependência é expectável, pela lógica imanente à sua missão, constituição e funcionamento.

Embora seja claro que as IT consideradas de sucesso procuram desenvolver a sua capacidade de autofinanciamento, as suas situações financeiras tendem a ser bastante débeis (Egreja, 1999).

A capacidade destas instituições se auto-financiarem é bastante diferenciada. Enquanto algumas instituições revelam condições para sobreviver através da prestação de serviços e de apoio às empresas, outras apresentam maior dificuldade devido à escassez de potenciais clientes.

Ao mesmo tempo que constitui um garante da sua sobrevivência, a dependência dos financiamentos externos está na origem de claras deficiências no funcionamento de grande parte das instituições.

Vários são os IC que referem os problemas decorrentes de atrasos nas transferências do financiamento base. As irregularidades nos pagamento dos projectos, nacionais e comunitários, constituem igualmente um factor de instabilidade na vida das instituições. As situações em que os problemas de financiamento não são tão visíveis encontram-se associadas a instituições que detêm o apoio privilegiado de algumas empresas. 
Os atrasos na aprovação de projectos são outro problema das IC\&T, tendo já estado associados a perdas de interesse e de oportunidade por parte de empresas envolvidas.

Os pressupostos subjacentes ao financiamento das IC\&T eram que, após o apoio inicial obtido, estas instituições deveriam criar as condições para manter e renovar o seu equipamento.

A capacidade de renovação do equipamento é bastante variável. Nalguns casos o que está em causa é essencialmente o desenvolvimento de actividades de carácter cognitivo, sendo os equipamentos relativamente acessíveis. Em algumas áreas os próprios profissionais podem actualizar parcialmente o equipamento. Noutras áreas requerem-se meios de mais difícil aquisição e manutenção, dificilmente comportados pelos projectos de investigação.

Um dos problemas das IC\&T mais próximas do mercado é o facto de não deterem capacidade para adquirir certo tipo de equipamento devido à escassez de potenciais utilizadores (com os riscos inerentes de onerar excessivamente as empresas utilizadoras ou de redundar em situações de não amortização no tempo de vida útil do equipamento).

A incapacidade das instituições adquirirem equipamento pelos seus próprios meios prende-se também com a dificuldade que elas revelam em cobrar os preços reais das tarefas que realizam. Frequentemente os preços praticados apenas permitem cobrir os custos de exploração, não prevendo quaisquer excedentes para realizar investimento. Há mesmo projectos que são realizados com um prejuízo significativo, seja porque o investigador não quis perder o projecto, seja por dificuldades de negociação por parte do investigador, seja por falta de cuidado na redacção dos contratos. Noutros casos verifica-se mesmo o não pagamento dos serviços prestados, referindo algumas instituições que não conseguem obter essas verbas pelo facto de não deterem uma estrutura de suporte para resolver este tipo de situações.

\section{A PROCURA POTENCIAL DAS IC\&T - DIMENSÃo E TIPO DE EMPRESAS}


Um dos factores explicativos da fraqueza das ligações que se continuam a verificar entre IC\&T e empresas são as características dos potenciais utilizadores dos serviços das primeiras. O tecido económico português é conhecido pela ausência de grandes empresas tecnologicamente evoluídas e pela predominância de pequenas empresas, tendencialmente de baixa intensidade tecnológica e que não reflectem grandes necessidades de inovação.

O facto de não haver uma forte tradição industrial no país e das empresas existentes se pautarem pela opção de tecnologias muito tradicionais, recorrendo às IC\&T apenas quando “obrigadas” ou quando surgem problemas inesperados, limita o estabelecimento de ligações mais duradouras ou consistentes entre os dois tipos de instituições.

Muitas empresas portuguesas laboram em regime de subcontratação, mediante as directrizes técnicas e tecnológicas dos clientes, o que se salda numa menor apetência para recorrerem às IC\&T. A opção quanto à aquisição de tecnologia é bastante centrada no factor custo, não se valorizando o desenvolvimento endógeno de competências.

A relação que os IC podem estabelecer com o sector empresarial situa-se num quadro marcado pela escassez de empresas de base tecnológica, pela reduzida valorização da tecnologia como factor de competitividade e pela fraca qualificação dos recursos humanos. Acrescem os custos de tal colaboração, dificilmente comportados por um tecido empresarial que denota claras fragilidades financeiras e de gestão. O facto das empresas estarem envolvidas muitas vezes num esforço de sobrevivência significativo, traduz-se na incapacidade de mobilizarem recursos para sustentar projectos de maior consistência tecnológica.

O leque de empresas de capital nacional com as quais as IC\&T mais próximas da universidade podem colaborar encontra-se quase exclusivamente circunscrito às Novas Empresas de Base Tecnológica (NEBT), às escassas empresas de elevada intensidade tecnológica e às situações pontuais de empresas de sectores tradicionais preocupadas com a inovação como forma de evolução estratégica.

Embora se possa estabelecer que o mercado potencial das IC\&T é em geral escasso, denotam-se porém situações variáveis, decorrentes da diferente procura e sofisticação tecnológica dos sectores de actividade económica. Isto apesar das IC\&T terem revelado uma clara dificuldade em segmentarem a sua base de clientes e potenciais clientes, efectuando caracterizações muito gerais do tipo e dos seus sectores de actividades das empresa com as quais mantêm contactos privilegiados. 
No caso dos INT/CTT, que assumem uma vocação horizontal de apoio à introdução de novas tecnologias e de estímulo à inovação, a sua base de potenciais clientes encontra-se limitada pela já identificada fraca receptividade das empresas face a opções tecnologicamente mais evoluídas. Porém, esta situação não é generalizável, dado que algumas destas instituições desenvolvem actividades determinantes para as empresas e respondem a necessidades tecnológicas de sectores de especialização competitiva.

Os CT, constituídos com o objectivo de apoiarem técnica e tecnologicamente sectores tradicionais de especialização produtiva, detêm à partida um potencial de utilizadores mais alargado. Apesar dos constrangimentos decorrentes da ausência de hábitos de inovação tecnológica por parte das empresas situadas no espaço nacional, tais limitações são menos evidentes pelo facto de alguns serviços prestados pelos CT serem vitais para a actividade empresarial. Também a configuração institucional dos CT potencia essa, dado que a sua concepção e gestão foi pensada para realizar a ligação a um tecido empresarial concreto e às suas necessidades específicas, sem que tal implique um down-grade na sua estrutura científica e tecnológica.

O sector Estado tem sido apontado como um dos actores privilegiados na dinamização e sustentação da procura de que as IC\&T são objecto (Larédo). Apenas em alguns casos pontuais, essencialmente na área da informática, a administração pública constitui um cliente de referência. Noutras áreas relevantes, associadas por exemplo ao ambiente, à energia, raramente surgiram como entidades de referência. Nalguns casos a administração local é inclusive considerada um factor dificultador da actividade das IC\&T.

O aproveitamento das capacidades instaladas nas IC\&T e a sua dinamização, por exemplo com base em estudos estruturantes que permitam perspectivar linhas de desenvolvimento do país, permanece assim em aberto.

\section{Processos de PROduÇÃo/ DI SSEMI NAÇÃO/ INTEGRAÇÃo dO CONHECIMENTO}

\subsection{Estrutura interna e de RH}


Nos IC as estruturas internas são claramente definidas em função das áreas de investigação dos responsáveis de laboratório.

No que se refere às IT, encontram-se situações bastante diversas. Enquanto os CT se tendem a organizar por áreas funcionais, vocacionadas para estruturar o contacto com as empresas, nas restantes IT a configuração interna tende a ser realizada em função das áreas de investigação dos universitários. Denota-se porém que algumas começam a criar estruturas centradas no desenvolvimento de áreas de negócio, que permitam dar resposta a problemas de forma integrada.

Uma das características evidentes de um número significativo de IC\&T é o facto de serem constituídas por recursos humanos ligados à universidade.

Em termos genéricos, os IC são as instituições que apresentam quadros próprios mais reduzidos. A lógica de constituição dos IC assentou no recurso ao potencial de investigação existente nas universidades, pelo que entre os seus colaboradores se encontram quer docentes quer investigadores em percurso de formação graduada ou pós-graduada. Pelos objectivos de funcionamento deste tipo de instituição, e pelos constrangimentos financeiros com que se debatem, a contratação de investigadores e de pessoal técnico e administrativo é bastante reduzida.

Assim, uma situação comum aos IC é o facto de deterem estruturas de apoio administrativo e suportes técnicos bastante insipientes, apresentando claras insuficiências em termos de apoio jurídico, financeiro e de gestão. Estas fraquezas saldam-se em grandes dificuldades de relação com outras instituições, e no subaproveitamento do potencial de investigação existente, dado que são normalmente os investigadores que se responsabilizam pela realização desse tipo de tarefas.

As lacunas em termos de recursos humanos e de suportes técnicos e administrativos não são tão evidentes nas IT, embora sejam claras algumas dificuldades aos dois níveis. São naturalmente as instituições com maior tradição de relação com o tecido empresarial que apresentam estruturas de suporte mais estabilizadas e consistentes.

Quer os CT quer os CTT analisados detêm os seus próprios quadros de colaboradores, ainda que podendo recorrer a docentes universitários para realizar actividades específicas, por exemplo de coordenação. No caso dos INT encontram-se situações mistas: nalguns casos existe o recurso privilegiado a universitários e bolseiros de investigação, noutros casos há um quadro de pessoal próprio relativamente estabilizado, complementado por universitários e consultores. 
A existência de quadros próprios de colaboradores é um dos aspectos mais discutidos quando se analisa o "modelo ideal” de IT. A génese das instituições financiadas pelo PEDIP foi marcada pelo incentivo à contratação de colaboradores, por forma a evitar que estas se constituíssem como meras extensões das universidades.

A questão dos quadros próprios tem sido alvo de discussão especialmente no caso dos INT por se considerar que esta opção pode redundar na falta de qualidade dos recursos disponíveis nas instituições, incapazes de reter as pessoas mais competentes após a sua formação. Alguns entrevistados referem que o "emprego seguro” conduziria a uma escassa motivação para procurar no mercado os meios necessários à investigação.

Torna-se porém evidente que o facto dos investigadores serem financeira e laboralmente independentes, e em muitos casos não obterem sequer qualquer compensação financeira pela colaboração que prestam, não estimula um envolvimento elevado nem a responsabilização face à evolução destas instituições.

As pressões de um sistema de emprego marcado por uma forte competição por RH qualificados, e as fracas recompensas que estas instituições têm para oferecer, poderão efectivamente saldar-se numa selecção negativa. Contudo, como realizar uma adequada gestão de pessoas que não estão “vinculadas” a uma instituição?

A existência de quadros próprios reflecte-se também na qualidade das relações com o exterior. As IC\&T posicionam-se de duas formas distintas quanto à realização dos trabalhos solicitados por empresas: em alguns casos contrata-se uma pessoa afecta apenas a esta actividade, noutros casos o trabalho de investigação é realizado no âmbito da graduação ou da pós-graduação de um aluno.

O facto do trabalho de algumas IC\&T assentar fortemente na formação graduada e pós-graduada leva a que os projectos sejam geridos e vocacionados para responder aos interesses pessoais dos investigadores envolvidos. A escassez de recursos envolvidos na realização de $I \& D$, o facto das empresas estarem habituadas ao financiamento destas actividades, de aceitarem a sua realização por um bolseiro, ou de se proporem pagar investigação abaixo do seu preço de custo, redunda numa tentativa de utilizar os recursos, respondendo simultaneamente a diferentes tipos de objectivos, com os custos que daí podem advir.

O recurso a jovens em processo de graduação ou pós-graduação é uma das razões mais avançadas para explicar os insucessos nos resultados finais de alguns projectos. 


\subsection{Gestão dos colaboradores}

A fraca capacidade de estabelecer políticas de gestão dos colaboradores é um dos constrangimentos mais evidentes nas IC\&T.

O facto de muitas IC\&T serem suportadas pela colaboração de docentes universitários tem subjacente uma contradição inequívoca, que resulta das pessoas serem remuneradas e avaliadas por uma instituição mas realizarem uma parte fundamental das suas actividades noutra instituição (e ser em função destas últimas que vão ser avaliadas pela primeira).

Tal contradição pode redundar num reduzido envolvimento face às IC\&T e aos seus objectivos, e gerar alguma desresponsabilização face aos seus resultados. A colaboração com as IC\&T poderá ter como único estímulo o acesso a meios de investigação que não se obtêm na universidade (mas que eventualmente se podem conseguir noutra instituição).

Em algumas instituições onde colaboram quadros próprios e docentes universitários, foram referidas coexistências algo conflituantes, derivadas de diferentes graus de envolvimento e responsabilização em função do vínculo dos investigadores.

O facto das IC\&T não deterem quadros próprios limita também a definição de políticas de GRH.

Nos IC, apenas em situações muito pontuais há compensações financeiras pela participação em projectos financiados por empresas. Mesmo relativamente aos órgãos de gestão se verifica que não existem compensações financeiras pela colaboração prestada.

Nestas instituições a obtenção de remuneração complementar proveniente do desenvolvimento de actividades de I\&D tende a ser rejeitada, sendo alvo de crítica as instituições ligadas à universidade que a praticam (por se considerar que tais práticas desvirtuam a missão universitária).

No caso dos CT e de alguns CTT que detêm quadros próprios significativos, é clara uma tendência para definir políticas tendentes à retenção e motivação dos colaboradores, como o estabelecimento de remunerações variáveis em função do alcance de objectivos e dos desempenhos individuais. 
Verifica-se que a prática de compensar financeiramente os investigadores não é generalizada nos INT. Nestas instituições encontram-se dois tipos de situações: em alguns institutos os investigadores não recebem qualquer tipo de compensação pelo facto de participarem em projectos; noutros casos há avenças e compensações financeiras pela participação em actividades de I\&D ou pela coordenação de equipas (surgindo a universidade como intermediária nesse pagamento). Esta dualidade de situações no que se refere às remunerações extra poderá ser explicada pelas diferenças que as áreas científicas apresentam quanto à facilidade de acesso a financiamentos, e quanto ao tipo de meios que suportam a investigação.

Este quadro leva a que nas IC\&T onde a colaboração com a indústria não implica qualquer tipo de compensação financeira, a cooperação só seja atractiva se as actividades a realizar permitirem obter resultados cientificamente relevantes, situação pouco comum no panorama português.

Porém, a importância que a existência de compensações financeiras poderá ter como factor de motivação para o estabelecimento de relações de colaboração com a indústria tem que ser relativizada. Em algumas áreas científicas, que detêm oportunidades de emprego a nível empresarial, enveredar por uma carreira de docência/investigação surge como uma opção de vida. O que motiva os investigadores é a curiosidade e o desafio intelectuais, e o reconhecimento que procuram é o da sua excelência científica, pelos seus pares.

A dificuldade em estabelecer políticas de gestão de recursos humanos estende-se à avaliação dos desempenhos.

O facto dos IC e de alguns INT tenderem a ser perspectivados como locais onde os docentes obtêm condições para investigar, e a liberdade de acção que detêm (pelo tipo de trabalho realizado mas também pela desarticulação entre estas instituições e as universidades), não permite a avaliação dos desempenhos dos indivíduos e dos grupos. O facto dos jovens investigadores tenderem a ser financiados através de bolsas, também limita o estabelecimento deste tipo de práticas.

Apesar do estatuto da carreira docente preconizar como funções destes profissionais a prestação de serviço docente, o desenvolvimento de investigação científica, a contribuição para a gestão democrática da escola e a participação em tarefas de extensão universitária, apenas a investigação tende a ser considerada em termos de progressão na carreira. A carreira universitária também não prevê qualquer tipo de apoio ao desenvolvimento de actividades de cariz empresarial.

Quer a publicação de patentes quer a participação em projectos industriais tendem a ser muito pouco valorizadas nos processos de avaliação. A dificuldade de avaliar os resultados de actividades 
realizadas com a indústria, por exemplo, apreciar o "valor de um protótipo”, são justificações avançadas para a desvalorização deste tipo de prática.

Os pressupostos da avaliação e da progressão na carreira académica justificarão uma menor apetência por parte dos docentes mais jovens em estabelecer relações com o sector empresarial, pelo facto de ainda não terem um estatuto que lhes permita aceitar, por exemplo, deixar de publicar por forma a proteger um segredo industrial, e pelo facto da sua carreira estar dependente da publicação em revistas cientificamente relevantes.

No que se refere aos bolseiros, a falta de incentivo para colaborarem com a indústria decorrerá das suas perspectivas e expectativas profissionais, que tendem a centrar-se nas universidades e nas instituições de I\&D. Acresce o facto da aprendizagem das práticas de relacionamento com as organizações e grupos ser parcialmente estruturada com base nos padrões institucionais vigentes, pelo que se as IC\&T não valorizarem certo tipo de relações com o exterior, mais dificilmente estas serão desenvolvidas.

Uma última limitação no que se refere à definição de políticas de gestão de recursos humanos prende-se com o estabelecimento de planos de carreiras. O facto das instituições não deterem estruturas sólidas limita o recurso a uma das mais poderosas formas de motivação e envolvimento institucionais.

Em termos de formação, no caso das instituições mais próximas da universidade, a aquisição de novos conhecimentos e competências decorre da dinâmica da própria investigação. Espera-se que os investigadores identifiquem as suas necessidades e obtenham os meios para as adquirir.

Nas instituições mais próximas do mercado o investimento em formação tende a constituir um factor estratégico fundamental, pela importância que a aquisição de novas competências assume para o tipo de actividade que desenvolvem.

Tradicionalmente os universitários tendem a ser encarados como individualistas. Se a actividade de investigação pode gerar esse tipo de fechamento, a lógica de gestão das instituições de I\&D potenciao, dado que ela está centrada nas aquisições e no trabalho individual.

A carreira docente e de investigação é sustentada pela qualidade da actividade científica realizada, não sendo na prática considerado o desenvolvimento de outro tipo de tarefas, seja de carácter institucional seja de extensão. As equipas de investigadores encontram-se em competição por recursos escassos, por vezes dentro da própria instituição. 


\subsection{A atracção/rotação dos recursos humanos}

Os CT são instituições onde a dificuldade de reter os RH se revela de forma significativa, provavelmente pela proximidade entre as competências dos seus RH e as necessidades das empresas.

Algumas IC\&T mais próximas da universidade assumem a mobilidade como fazendo parte da sua missão, procurando essencialmente minimizar os seus impactos organizacionais.

Também nos INT/CTT que detêm quadros próprios se referem as pressões do mercado sobre os seus colaboradores tecnicamente melhor preparados.

As alternativas que algumas instituição têm identificado para manter uma base de colaboradores relativamente estável passam quer pelo recurso a factores de motivação intrínseca (associados à qualidade do trabalho realizado, à qualidade do clima interno, ao envolvimento em aspectos relacionados com a gestão), quer por práticas de remuneração diferenciadas (mais elevadas para um "núcleo duro" de RH e menos favoráveis para os restantes).

No caso dos IC a rotação dos recursos humanos está associada a grandes preocupações quanto à capacidade para melhorar/manter a qualidade da investigação.

A tendência para a diminuição do número de alunos nas universidades, a escassez de quadros, a diminuição das verbas disponíveis para a investigação, conjugam-se num quadro potencialmente negativo, que pode redundar na incapacidade de manter a qualidade científica que se evidencia actualmente em algumas instituições.

A dificuldade de atrair novos investigadores não é generalizável a todos os IC. As áreas científicas apresentam potenciais de atracção distintos pelo facto da sua “actualidade” não ser idêntica.

Porém, as condições facultadas aos potenciais investigadores não constituem um factor de atracção, pelo reduzido montante que as bolsas de investigação representam em áreas tecnológicas com maior procura, e pela ausência de perspectivas de carreira numa realidade universitária marcada pela limitação e esgotamento dos quadros. 
Apesar dos IC funcionarem como instituições onde apenas é expectável a "permanência” de docentes universitários, a excessiva rotação de investigadores coloca dificuldades quanto à continuação de actividades e linhas de investigação. Esta situação é mais notória em localidades pequenas, que conseguem atrair pessoas para realizarem a sua formação pós-graduada, mas de onde estas retornam quando essa formação termina.

Um dos problemas que emergem na realização de projectos é exactamente a sua descontinuidade, decorrente das dinâmicas da vida académica e das mobilidade dos investigadores. Por vezes estas reflectem-se na necessidade de "reiniciar” actividades já contratadas.

\subsection{A formação de equipas de investigação - transdisciplinaridade e colaboração interna}

O actual modo de produção do conhecimento (Gibbons et alli, 1997), assente na transversalidade dos conhecimentos, permite preconizar a importância de equipas transdisciplinares e inferir as vantagens obtidas por organizações detentoras de valências/conhecimentos diversificados e complementares.

As referências à transdisciplinaridade na produção de conhecimento foram bastante variáveis.

Centrando-nos nos exemplos das instituições consideradas de maior sucesso, verifica-se que esta não parece ser uma variável explicativa desse sucesso. Algumas instituições caracterizam-se por deterem colaboradores de uma mesma área disciplinar (essencialmente no caso dos IC), outras por uma diversidade e complementaridade de áreas disciplinares.

A existência de equipas de colaboradores com formação diferenciada parece encontrar-se associada à base de conhecimentos mobilizado, ela própria sustentada por várias disciplinas ou não.

A questão que se pode colocar é se o sucesso possível com a limitação das áreas científicas não decorrerá de uma actividade essencialmente centrada na produção e disseminação do conhecimento, em detrimento do estímulo à sua integração. A diversidade de perspectivas será fundamental numa lógica de análise das situações e problemas de forma integrada, melhorando a qualidade das relações e serviços que se prestam.

No que se refere às práticas de colaboração inter-equipas, algumas IC\&T consideraram a tendência para o fechamento dos grupos de trabalho um limite à optimização das capacidades existentes. A falta de ligação entre as equipas será explicada pelo tipo de instituição, pelo tipo de actividade 
desenvolvida, mas também pelas exigências decorrentes de uma carreira centrada no número, no relevo científico e na urgência das publicações. Embora se tenham encontrado instituições que definem nos seus objectivos a promoção da colaboração interna, nem sequer o reconhecimento público pelo apoio prestado por um determinado indivíduo se encontra salvaguardado, o que limita os efeitos reais de tais esforços.

\subsection{Formas de gestão}

O perfil dos gestores das IC\&T tem sido avançado para explicar os resultados diferenciados que estas instituições apresentam, especialmente no que se refere às IT.

O pendor mais universitário ou mais empresarial na gestão das IT tem sido um factor de discussão que se polariza, por um lado, em torno da necessária sensibilidade às questões empresariais para poder sustentar uma ligação a este sector (e ao facto das competências científicas não se traduzirem em competências de gestão) e, por outro, à exigência de sensibilidade e conhecimento sobre as questões da ciência e tecnologia (por estar em causa a produção e "transacção" de conhecimento e não de outro tipo de bem).

Uma vez mais se verifica a expectável diferença entre CT e IC e uma realidade mista nos CTT/INT. Os CT são geridos por gestores profissionais numa perspectiva claramente empresarial. Pelas suas características intrínsecas, a gestão dos IC é assegurada por docentes universitários, que acumulam esta função com as suas restantes actividades. Nos INT e nos CTT a gestão é assegurada quer por gestores profissionais quer por universitários (por vezes com apoio de gestores).

Se os CT auscultados se notabilizam pelo seu sucesso e na sua totalidade são geridos por gestores profissionais, o que se traduz na assunção da instituição como empresa, nas restantes IT já não é possível concluir de forma linear pelas vantagens de uma gestão “estritamente empresarial”.

O sucesso encontra-se também em instituições geridas por universitários que assumem as funções de gestão. Este facto sublinha a necessidade dos gestores apresentarem afinidades e serem reconhecidos cientificamente pelos investigadores. Porém, a sensibilidade às questões associadas à geração do conhecimento não é razão suficiente para explicar a eficácia destas instituições. Esta é também explicada por princípios de gestão estratégica e por grandes preocupações face às questões do mercado. Assim, é a existência dos dois tipos de valência: conhecimento científico e competências de gestão, que explica tais casos de sucesso. 
No caso dos IC (e em menor grau em alguns INT/CTT) as dificuldades identificadas a nível de gestão prendem-se essencialmente com uma menor disponibilidade dos responsáveis, decorrente da acumulação de funções.

Nalguns casos verificam-se dificuldades de reconhecimento do responsável da gestão pelos seus pares, sendo o próprio a revelar dificuldade em exercer essa função. Tais situações resultam em dificuldades na tomada de decisão e na aceitação da sua legitimidade.

O facto dos investigadores optarem por pertencer ou não a uma determinada instituição de investigação dificulta o estabelecimento de regras ou princípios que colidam com os seus interesses, devido a potenciais abandonos e aos riscos de perda de massa crítica. Esta dificuldade será mais marcante nos IC, dado que o seu financiamento base depende do número de doutorados (para além da classificação obtida).

A gestão das IC\&T também se diferencia na forma como estas se posicionam face ao exterior e na forma como divulgam a sua actividade.

Os IC tendem a rejeitar actividades de marketing, por se considerar esta prática desajustada face à sua vocação e por não se deterem os recursos (financeiros, de tempo e de competência) para as levar a cabo. A divulgação deste tipo de instituição é realizada pelos veículos e numa lógica meramente académica.

Na maioria das outras IC\&T é atribuída uma importância significativa às actividades de marketing. Isto apesar das redes de contactos pessoais justificarem muitas das “encomendas” conseguidas.

As instituições que apostam fortemente no marketing sublinham a necessidade de um contacto muito personalizado com os potenciais clientes, promovidos por responsáveis de equipas ou por técnicos, consoante as opções das instituições.

Uma perspectiva comum a todas as IC\&T é que o contacto com as empresas deve ser realizado por indivíduos que dominam as actividades a promover, isto porque a capacidade de "sensibilizar" as empresas está relacionada com a ancoragem dos contactos em situações concretas ou na antecipação de problemas.

\subsection{Cultura institucional}


A existência de valores partilhados entre os colaboradores de uma instituição é algo comum às instituições de maior sucesso e é estimulada pelos responsáveis das instituições e grupos. Os valores partilhados são de dois tipos:

1) a excelência que se perspectiva para a instituição e para a sua actividades científica, a importância que a actualização e o desafio intelectuais representam, a autonomia e flexibilidade detidas pelos investigadores;

2) a percepção da missão da instituição, seja no seu pendor mais universitário, seja na sua missão de ligação à indústria.

A assunção da instituição como uma realidade da responsabilidade de todos, em detrimento de uma lógica de subgrupos, é um valor encontrado apenas em alguns casos.

\subsection{0 acesso a fontes de conhecimento - as relações externas}

A maior parte das IC\&T assume uma clara estratégia de promoção de ligações privilegiadas com a instituições produtoras de conhecimento. Se nalguns casos as relações se estabelecem dentro do país, noutros casos (especialmente nas IC\&T com maior sucesso) as ligações são estabelecidas com instituições externas de referência.

Estas redes de conhecimentos são consideradas fundamentais como forma de conseguir a actualização e aprendizagem de técnicas, mas também como forma de obter prestígio para as próprias instituições e de obter meios para a investigação.

O que parece ser fundamental para o estabelecimento de tais ligações são os contactos pessoais. As opções pelos países com os quais se estabelecem relações privilegiadas (seja através da mobilidade de investigadores ou da realização de projectos comuns), decorrem do contacto prévio de investigadores seniores, normalmente estabelecidos aquando da realização dos seus doutoramentos.

Denotam-se algumas relações privilegiadas entre IC\&T que ajudam a explicar o sucesso que estas têm obtido no desempenho da sua missão. Estas situações decorrem de ligações muito próximas e bem definidas quanto ao papel e à função complementar das instituições. Encontraram-se apenas duas situações muito claras de “continuidade” entre IC e INT. Os IC são responsáveis pela produção 
de conhecimento de cariz mais fundamental, e todas as ligações a empresas são realizadas pelos INT. Os investigadores são muitas vezes os mesmos, os equipamentos são partilhados/complementares, o que varia é a instituição que acolhe os diferentes projectos. Esta situação apresenta grandes vantagens dado que as ligações às empresas são formalizadas pelas instituições e pelos investigadores que têm maior sensibilidade face a essa realidade. As vantagens derivam igualmente da libertação dos IC de algumas tarefas processuais, por exemplo de contratação ou de gestão de patentes, para as quais não apresentam uma vocação tão nítida.

Noutras instituições esboça-se o mesmo tipo de complementaridade mas em moldes menos frutuosos, devido a alguma rejeição da ligação à indústria por parte dos universitários. Uma das razões para se objectar ao estabelecimento de uma relação mais próxima entre os dois tipos de instituição prende-se com o facto das IT deterem empresas como associadas, o que se considera colidir com a missão universitária. Este receio poderá ser justificado pelo risco de perda de autonomia na investigação, atestado por situações em que empresas associadas a IC criam dificuldades nas ligações a empresas suas concorrentes, e resistem a opções de investigação que possam colidir com os seus interesses.

A relação com os laboratórios de Estado é uma questão delicada do SCT, a qual poderá ter na origem a indefinição das funções dos vários agentes, e a prática de duplicação de organismos como forma de superar a ineficácia de alguns. Em termos globais verificou-se que a interacção entre IC\&T e os laboratórios de Estado é muito limitada.

\subsection{Como se avaliam}

As IT denotam algumas preocupações em efectuar a avaliação interna da sua actividade. Porém, as referências às práticas de auto-avaliação vão pouco além de uma análise de resultados em termos de centros de custos. A maior parte das instituições tende a aferir a satisfação dos clientes através da sua fidelização e retorno.

Das instituições mais próximas do sector empresarial, são os CT que revelam maior preocupação em apreciar a satisfação dos seus clientes face aos serviços adquiridos através de instrumentos especificamente elaborados para o efeito (por razões que se prendem também com a sua certificação pela qualidade).

Verifica-se que os INT mais próximos do "pólo da ciência” assumem preocupações de avaliação muito centradas na qualidade da investigação. 
A grande maioria do IC não tem qualquer metodologia interna de avaliação das suas actividades, esperando-se que sejam os responsáveis pelos grupos de investigação que acompanhem e verifiquem a prossecução das tarefas. É a avaliação da FCT que constitui o quadro de referência destas instituições.

\subsection{Como disseminam o conhecimento}

A forma como as instituições gerem e disseminam o conhecimento que produzem pode assumir um carácter mais ou menos estratégico, quer no que se refere à geração de novo conhecimento quer no que se refere às suas relações com outras instituições.

A situação mais referenciada em termos de disseminação interna de resultados, essencialmente em IC\&T mais próximas da universidade, foi a promoção de encontros/seminários periódicos de divulgação das actividades em curso e dos seus resultados. Em algumas instituições foi referido que se tinham abandonado progressivamente esse tipo de práticas. Nas razões avançadas para tal ocorrência por parte dos responsáveis de laboratório, foram identificadas restrições de tempo. Alguns investigadores referiram porém a falta de interesse dos responsáveis de laboratório, que teve efeitos inevitáveis na motivação para realizar esse tipo de actividade.

Um INT salienta-se relativamente às restantes instituições pelo facto de alguns grupos aproveitarem os eventos destinados à disseminação interna de conhecimento para estabelecerem relações mais próximas e "aculturar" os clientes, convidados a estar presentes para adquirirem sensibilidade face às questões e problemas específicos da investigação.

No que se refere à disseminação externa dos resultados, o posicionamento das diferentes IC\&T é, como seria de esperar, bastante diferente.

No caso dos IC, a disseminação é muito centrada nos pares, sendo privilegiada a publicação de artigos e livros e a realização de comunicações. São igualmente promovidos seminários, embora com menor relevo.

No caso das IT denotam-se estratégias de disseminação viradas para o exterior, nomeadamente através de publicações específicas. A realização de seminários e conferências destinadas a clientes e potenciais clientes é uma prática seguida por grande número de instituições. 
Uma das funções que se podem atribuir às instituições produtoras de ciência é a disseminação de conhecimento para a sociedade em geral. Poucas instituições assumem essa missão. No caso de alguns IC essa disseminação é limitada aos contactos com escolas do ensino secundário, uma das orientações da FCT.

Denota-se que a prática de divulgação científica para a sociedade, por exemplo o contacto com jornais de grande divulgação ou com a televisão, é rejeitada por alguns investigadores, por ser considerada consumidora de tempo e menos nobre face às suas funções. Acrescem ainda os problemas decorrentes de uma divulgação menos cuidada e propagandística de certas actividades, que acabam por conduzir à rejeição dessa prática.

\subsection{Como estimulam a integração do conhecimento}

Para além das actividades associadas à realização de actividades de certificação, teste, licenciamento, de investigação por contrato e consultoria, as IC\&T têm na formação e na mobilidade duas formas privilegiadas de suporte à integração do conhecimento.

\subsubsection{A formação}

A integração de conhecimento pode ser realizada num contexto individual, sem interacção com os produtores do conhecimento, se os indivíduos estiverem na posse de todas as ferramentas conceptuais que permitem a sua compreensão e integração. Quando o conhecimento assume a aquisição de competências psico-motoras, ou quando a sua complexidade não permite uma apropriação individual, a interacção com os produtores de conhecimento (entendidos em sentido lato) torna-se fundamental.

A formação assume-se por isso como uma tarefa essencial na actividade das IC\&T.

A organização de actividades de formação pós-graduada ou destinada a profissionais de qualificação intermédia, é uma actividade muito importante para as IC\&T mais próximas do mercado. Algumas instituições investem fortemente na formação por a considerarem básica no âmbito da sua missão, outras porque esta constitui uma forma de equilibrar situações financeiras débeis.

Pela sua lógica interna, nas IC\&T mais próximas da universidade só é realizada formação pósgraduada. Uma das razões avançadas para não promover formação de outros níveis são as 
burocracias associadas a esta actividade (nomeadamente no caso da formação financiada) e os problemas logísticos que tal prática implica.

A formação (não financiada) para quadros e técnicos superiores foi apontada por algumas IT como uma importante forma de promoção junto das empresas, tal como os seminários. Para além de possibilitar o conhecimento da instituição, estas actividades constituem uma oportunidade para revelar as valências existentes, tendo sido evidentes os retornos de tais eventos.

\subsubsection{A mobilidade de recursos humanos}

A aprendizagem presencial é requerida essencialmente quando o conhecimento mobilizado tem uma componente psico-motora e quando as actividades não podem ser reproduzidas de forma linear. Tal interacção não se torna necessária quando o conhecimento se baseia em actividades com carácter abstracto, é "facilmente" transferível e apreensível, porque codificado. Porém, a mobilidade pode constituir um instrumento privilegiado para potenciar competências relacionadas com diferentes contextos de utilização e aplicação do conhecimento.

Em termos globais a mobilidade é uma situação pouco comum, não obstante as referências maioritariamente positivas aos casos em que tal acontece.

Torna-se evidente a dificuldade em estabelecer este tipo de prática devido à ausência, na maior parte das empresas, de meios internos e de técnicos disponíveis para se envolverem neste tipo de actividade.

O facto dos investigadores poderem trabalhar nas empresas e de colaboradores de empresas trabalharem em IC\&T, constitui uma forma de gerar, difundir e facilitar a integração de conhecimento, mas também um veículo para fortalecer a qualidade das relações e para minimizar os riscos de algum desvirtuamento ou incompreensão dos objectivos das actividades a desenvolver.

Para além das vantagens inerentes a uma produção in especifico do conhecimento, e da sua mais fácil integração, a mobilidade de investigadores para as empresas poderá obstar a eventuais situações de "apadrinhamento indevido" das actividades realizadas, dado que as estratégias pessoais se entrecruzam com as estratégias institucionais, e por vezes contribuem para dificultar ou mesmo terminar as relações de cooperação. 
Já a mobilidade entre IC\&T, especialmente a que envolve instituições de I\&D ou de interface estrangeiras é prática comum, mesmo no caso das instituições mais próximas do mercado. Esta mobilidade constitui não só uma forma de aprendizagem e desenvolvimento de técnicas, mas também uma estratégia de fortalecimento das relações inter-institucionais. O benchmarking realizado por várias IC\&T passa pela mobilidade temporária de técnicos e investigadores.

O contacto com entidades prestigiadas do exterior é algo comum à maior parte das IC\&T consideradas de maior sucesso. Tal relação decorre do impacto que parceiros de referência mundial têm junto das empresas e dos organismos financiadores, mas também da sua importância para a aprendizagem de metodologias e formas de organização interna.

\section{QUE I MPACTOS ESTÃO A GERAR NAS EMPRESAS?}

\subsection{As relações entre empresas e centros de I\&D}

Um dos objectivos deste trabalho foi procurar descortinar o aproveitamento que as empresas nacionais realizam da infra-estrutura científica e tecnológica instalada no país.

Os resultados obtidos através do inquérito por questionário permitem concluir por uma relação limitada entre as empresas e centros de I\&D: apenas 15,9\% das 687 empresas inquiridas responderam manter esses contactos. Tais contactos residem essencialmente na testagem de produtos e de equipamentos, e em contactos informais com investigadores.

Quando inquiridas quanto aos resultados dessa relação as empresas identificaram a melhoria/concepção de produtos e, de forma menos nítida, a resolução de problemas de produção e concepção. Apenas três empresas identificaram o recrutamento de pessoas a partir dos centros de I\&D.

Questionaram-se as empresas que mantinham contactos com centros de I\&D sobre as suas dificuldades de interacção com essas instituições. As respostas incidiram essencialmente: na dificuldade dos centros de I\&D resolverem os problemas da empresa; nos prazos de realização; na dificuldade em contactar os interlocutores adequados; na falta de capacidade financeira para realizar projectos. As diferenças de linguagem não foram consideradas relevantes. 
É possível distinguir as empresas que mais tendem a colaborar com centros de I\&D em função de algumas variáveis.

A dimensão das empresas é uma das variáveis relevantes. Através de um teste de diferenças de médias foi possível concluir, com elevados níveis de significância, que são as empresas de maior dimensão que mais tendem a manter contactos/relações de cooperação com centros de I\&D. ${ }^{3}$

Os resultados do teste de diferenças de médias revelam também que a existência de contactos/relações de cooperação com centros de I\&D tende a ser mais elevada nas empresas com maior antiguidade. ${ }^{4}$

A existência de capital estrangeiro foi outra variável que se considerou poder explicar o comportamento das empresas quanto ao desenvolvimento de actividades de I\&D. A realização de um teste de diferença de médias entre o indicador de actividades de $I_{\&} \mathrm{D}^{5}$ e o capital estrangeiro revela que sensivelmente o dobro das empresas com alta I\&D possuem uma parte de capital estrangeiro ${ }^{6}$, apresentando as empresas com capital totalmente nacional e com capital totalmente estrangeiro uma menor percentagem de respostas em alta $I \& D .^{7}$ As empresas que mais tendem a manter contactos/relações de cooperação com centros de I\&D detêm capital maioritariamente nacional.

Procurou-se também determinar se o recurso a actividades de I\&D estaria associado à pressão concorrencial sentida por parte das empresas e a factores relacionados com o mercado.

Os sectores diferenciam-se entre si pelo tipo de aquisição tecnológica e pelo grau de investimento em I\&D que realizam. Porém, dentro do mesmo sector denotam-se diferenças entre empresas que, embora utilizando a mesma tecnologia, se encontram sujeitas a pressões de mercado completamente distintas. São as empresas sujeitas a uma grande competição externa e a margens de lucro muito reduzidas que mais tendem a colaborar com as IC\&T.

\footnotetext{
${ }^{3} \alpha=.000$

${ }^{4} \alpha=.006$

${ }^{5}$ Por se saber que a maior parte das empresas situadas no espaço nacional não promove actividades de I\&D, assumiu-se um conceito de desenvolvimento de actividades de I\&D bastante lato. Assim, para além do desenvolvimento de actividades de I\&D, considerou-se que a aquisição de serviços de I\&D e a existência de contactos/relações de cooperação com centros de I\&D poderiam ser utilizados como indicadores do comportamento das empresas a esse nível. Foi criado um indicador de actividades de I\&D com base em quatro variáveis: aquisição de serviços de I\&D, realização de actividades de I\&D, contactos/relações de cooperação com centros de I\&D, recurso a centros/instituições de I\&D para resolver problemas de produção, tendo as empresas sido dicotomizadas em função de apresentarem alta I\&D e baixa I\&D. Todas as correlações item/indicador se revelaram significativas.

${ }^{6} \alpha=.002$

${ }^{7} \alpha=.000$. A baixa I\&D das empresas com capital totalmente estrangeiro pode ser explicada pelo facto das suas actividades
} 
Assim, analisou-se a relação que poderia existir entre as práticas de I\&D e a percepção da evolução da concorrência, a existência de actividades de exportação, a existência de certificações, a venda de produtos com marca própria e, finalmente, as vantagens concorrenciais que as empresas consideravam efectivamente possuir.

Relativamente à primeira variável verifica-se que a percepção da evolução da concorrência não está associada à existência de contactos/relações de cooperação com centros de I\&D: a grande maioria das empresas considera que aquela aumentou.

Relativamente às restantes variáveis verifica-se uma associação entre as características mais distintivas em termos de mercado e a tendência para as contactarem/manterem relações de cooperação com centros de I\&D: as empresas exportadoras, as que vendem com marca própria, as que se encontram certificadas e vendem produtos certificados apresentam uma clara associação a esse tipo de prática.

No que se refere à ponderação dos factores de competitividade mais relevantes concluiu-se que as empresas que mantêm contactos/relações de cooperação com centros de I\&D tendem a considerar que a assistência pós-venda os recursos humanos qualificados e os produtos novos/melhoria de produtos fazem parte dos seus factores de competitividade muito importantes.

\subsection{Efeitos da actividade das IC\&T na capacidade competitiva e inovadora das empresas}

As empresas que mantêm um contacto mais continuado com IC\&T avaliam de forma globalmente positiva os resultados dessa colaboração, reconhecendo a importância e contributo dessas colaborações para o desenvolvimento das suas actividades (mesmo que se efectuem algumas críticas ao funcionamento das instituições).

Segundo a maior parte das empresas, não é possível quantificar os resultados obtidos pela cooperação com IC\&T. Algumas empresas referem que existem retornos tangíveis, associados ao desenvolvimento de produtos novos, de tecnologias e à resolução de problemas, mas existem outros retornos não quantificáveis, decorrentes da geração de conhecimento na empresa, o qual é utilizável em diferentes situações. Por exemplo, a colaboração em projectos permite a geração interna de

de I\&D serem realizadas no país de origem ou noutros locais em que se encontram implantadas 
know-how que pode jogar a favor das empresas em contactos comerciais, pela imagem de consistência que é transmitida quando se analisam problemas. Para algumas empresas, o retorno da colaboração é “medido”, de forma indirecta, através da liderança no mercado ou da capacidade de continuar a desenvolver e melhorar processos e produtos.

As empresas que desenvolvem relações de colaboração mais permanentes, financiando elas próprias alguns projectos, assumem que os investimentos só podem ser rentabilizados a médio prazo, sendo os seus resultados superiores à criação/melhoria de produtos/processos.

Através das entrevistas não foi por isso possível identificar impactos quantitativos da colaboração das instituições de I\&D nas empresas. Nenhuma empresa esteve em condições de quantificar esse retorno nem pareceu considerar tal prática necessária.

A análise do impacto da relação com instituições de I\&D na capacidade inovadora e competitiva das empresas foi também analisada através do inquérito por questionário.

São as empresas com competitividade elevada ${ }^{8}$ que mais tendem a manter contactos/relações de cooperação com centros de I\&D. ${ }^{9}$ Denota-se igualmente uma clara tendência para as empresas com inovação elevada ${ }^{10}$ manterem esses contactos/relações de cooperação. ${ }^{11}$

Umas das questões que se pretendia determinar através do inquérito era se a existência de contactos mais prolongados com centros de I\&D estaria associada a comportamentos mais inovadores.

A duração dos contactos identificada pelas empresas inquiridas é relativamente curta, na maior parte dos casos inferior a dez anos (algo congruente com a juventude de muitas IC\&T e outras instituições

\footnotetext{
${ }^{8}$ Atendendo à impossibilidade de identificar o ganho de quotas de mercado, o crescimento das empresas ou a sua rendibilidade, a competitividade foi inferida a partir de um indicador de performance económica: cash flow/dimensão da empresa. Este indicador apresentou correlações significativas com o crescimento do volume de vendas e com a taxa de variação do volume de vendas entre 1996 e 1998, bem como com a rentabilidade do activo económico em 1998. O rácio cash flow/dimensão foi dicotomizado em dois grupos de empresas: o grupo de baixa competitividade incluiu as empresas que apresentavam valores métricos inferiores ao percentil 47 e o grupo de alta competitividade incluiu as empresas que apresentavam valores superiores ao percentil 53. ${ }_{9}^{9} \alpha=.000$; phi $=.227$

${ }^{10} \mathrm{O}$ indicador de Inovação foi construído com base na combinação de 11 itens cujas correlações se revelaram significativas. Estes itens foram os seguintes: 1) Introdução nos últimos cinco anos de produtos completamente novos; 2) Introdução nos últimos cinco anos dos mesmos produtos melhorados; 3) Melhoria nos produtos por mudança nas matérias primas; 4) Melhoria nos produtos por mudança no processo de fabrico; 5) Melhoria nos produtos por mudança na qualidade do produto; 6) Melhoria nos produtos por mudança no design do produto; 7) Vantagem concorrencial importante: produtos novos/melhoria nos produtos; 8) Vantagem concorrencial importante: novos processos produtivos; 9) Vantagem concorrencial importante: novos equipamentos; 10) Houve reestruturações no processo produtivo nos últimos dois anos; 11) Houve criação de novos produtos ou mudança nos produtos nos últimos dois anos. A partição das empresas foi efectuada pela mediana.

${ }^{11} \alpha=.000$; phi $=.190$
} 
criadas no âmbito dos fundos estruturais). Apenas dezasseis empresas referiram contactos com elevada antiguidade (>15 anos).

O teste $t$ aplicado ao indicador de inovação e à variável anos de cooperação revelou uma clara associação entre ambos. ${ }^{12}$ A média da duração do contacto das empresas com baixa inovação é 5,71 e das empresas com alta inovação é 9,92.

Esta situação será expectável se considerarmos que, como foi sendo referido por vários entrevistados, o que está em causa no relacionamento com as empresas é a construção de relações de confiança entre actores. É através de um trabalho a prazo que se vai efectuando um ajustamento e se vão estabelecendo as "regras” da relação entre as duas partes. A existência de contactos mais prolongados certamente se reflectirá na criação de sinergias e no acesso a informação em condições mais vantajosas. Por outro lado, relações mais prolongadas podem estar na origem de processos de aprendizagem organizacional e de endogeneização de competências, que permitem um comportamento mais inovador por parte das empresas.

Quando se procurou determinar eventuais associações entre a antiguidade do contacto com centros de I\&D e a competitividade, não se descortina qualquer relação entre estas variáveis.

Procurou-se caracterizar de forma mais aprofundada o tipo de procura que as empresas efectuam nos centros de I\&D em função do seu comportamento inovador e competitivo.

No que se refere à primeira variável verifica-se que as empresas com alta inovação são as que mais recorrem com o objectivo de conceber/melhorar produtos e resolver problemas específicos. Já não se verifica a mesma associação com o indicador de competitividade utilizado.

O contacto com o objectivo de melhorar processos não se distingue em função do grau de inovação das empresas (ainda que exista uma maior percentagem de empresas de alta inovação a recorrer com este tipo de objectivo). Este facto poderá estar relacionado com uma tendência frequentemente apontada nas entrevistas realizadas: a tendência para as empresas adquirirem tecnologias "com chave na mão”, não procurando grandes desenvolvimentos a este nível.

A maioria das empresas que recorrem aos centros de I\&D para conceber novos produtos/melhorar produtos são as que vendem com marca própria e as que têm produtos certificados.

${ }^{12} \alpha=.002$ 
As empresas que exportam tendem igualmente a recorrer aos centros para conceber/melhorar produtos, e para melhorar os processos de produção.

As empresas foram inquiridas quanto às razões para não contactarem os centros de I\&D. Um dos resultados mais salientes foi a percentagem de empresas (38,3\%) que considera responder a todas as suas necessidades. Isto significa que sensivelmente um terço das empresas inquiridas não encontra vantagem em recorrer a centros de I\&D, mesmo numa envolvente marcada pelo acréscimo da concorrência. Este resultado pode ser explicado por várias razões: a tradicional miopia atribuída à indústria portuguesa, que passa pela não valorização de factores de competitividade mais estratégicos, pela preocupação com o curto prazo, pela falta de visão, mas também poderá ser atribuído à incapacidade dos centros de I\&D se conseguirem apresentar como um valor acrescentado para as empresas. ${ }^{13}$

Nas razões para o não contacto com os centros de I\&D são ainda de referir o seu desconhecimento $(25,1 \%)$ e o desconhecimento dos investigadores a contactar $(14,9 \%)$.

Procurou-se identificar se as razões evocadas para o não estabelecimento dos contactos variavam em função da inovação e da competitividade apresentadas pelas empresas: as empresas com baixa inovação tendem a referir mais o desconhecimento dos centros de $I \& D$, enquanto as empresas com alta inovação tendem a evocar a fraca capacidade desses centros.

Em termos de competitividade, verifica-se que as empresas com baixa competitividade avançam mais o desconhecimento dos centros de I\&D e a fraca qualificação dos seus próprios recursos humanos.

Colocou-se como hipótese que a existência de comportamentos inovadores e a maior competitividade fosse acompanhada por dinâmicas específicas de gestão dos colaboradores. Assim, procurou-se determinar se os movimentos de recrutamento e selecção/saída de colaboradores se encontravam associados a resultados distintos no desempenho das empresas.

Através de um teste de diferença de médias verificou-se que as empresas com alta inovação tendem a apresentar valores mais elevados quer no recrutamento, quer na saída de colaboradores com o $9^{\circ}$ ano e no recrutamento de colaboradores com o $12^{\circ}$ ano e com ensino médio/superior.

\footnotetext{
${ }^{13}$ Quando inquiridas sobre as instituições a que recorrem para resolver problemas de produção, 30,1\% das empresas referiram os fornecedores, 15,8\% identificaram os centros tecnológicos, 11,3\% entidades estrangeiras e 9,6\% identificaram instituições de I\&D.
} 
No que se refere à competitividade verifica-se que apenas o recrutamento de pessoas com o $12^{\circ}$ ano apresenta valores significativos, sendo que as empresas com alta competitividade tendem a recrutar mais pessoas com este nível de escolaridade.

Estes dados certamente expressarão a tendência para um acréscimo progressivo do nível de escolaridade dos colaboradores das empresas, tornado necessário num contexto produtivo marcado pela complexificação e abstracção das operações. A existência de recursos humanos qualificados poderá assim constituir uma estratégia das empresas que apresentam simultaneamente características mais positivas em termos de competitividade e inovação.

Recorde-se que a existência de RH qualificados como vantagem competitiva muito importante estava associada às empresas que responderam cooperar com centros de I\&D. No decurso das entrevistas em empresas bastante inovadoras e/ou que realizam actividades de I\&D foram efectuadas várias referências à importância da qualificação dos recursos humanos.

Outra das questões que se colocou foi se existiria alguma relação entre a área de formação dos colaboradores, as actividades de I\&D desenvolvidas e o comportamento inovador e competitivo das empresas. Isto porque se considerou que áreas ligadas às ciências ditas exactas poderiam facilitar o contacto com instituições de I\&D, pelos conhecimentos prévios e linguagens comuns.

Analisando a correlação/associação entre as variáveis indicador de actividades de I\&D e área de licenciatura verificam-se resultados diferenciados em função das áreas de licenciatura. Há valores significativos em economia/gestão, engenharia mecânica, engenharia electrónica/informática e outras engenharias: as empresas com alta I\&D apresentam valores médios mais elevados nestas áreas de formação escolar.

Também através da comparação dos valores médios das empresas com baixa inovação e alta inovação se verificou uma associação entre a inovação das empresas e a existência de colaboradores nas áreas de economia/gestão, informática, e outras engenharias. Estas áreas estão associadas a médias mais elevadas em alta inovação.

A relação entre a área de licenciatura dos colaboradores e a competitividade da empresa revela que há uma diferença de valores médios nos casos da economia/gestão, sociologia/psicologia/recursos humanos e engenharia mecânica. Estas áreas de licenciatura estão associadas a médias mais elevadas em alta competitividade. 
Embora não se encontrem explicações definitivas para estes resultados, que poderão ser explicados pelo tipo de indústria em que os quadros trabalham e pelas características mais ou menos dinâmicas e inovadoras das diferentes áreas disciplinares (por exemplo a informática e a engenharia electrotécnica/informática), verifica-se que a economia/gestão surge sempre associada quer à inovação alta, quer à competitividade alta, quer à I\&D alta, o que poderá estar relacionado com a existência de competências específicas que se expressam em diferentes atitudes nas organizações.

São as actividades de I\&D que estão na origem de maior inovação por parte das empresas? Ou a I\&D constitui um factor de diferenciação dentro de uma estratégia mais global em que se incluem outros factores como os RH?

Embora não seja possível estabelecer relações lineares entre o investimento em I\&D nas suas diferentes formas e o comportamento inovador e competitivo das empresas, nem quantificar os impactos das formas de cooperação existentes, afigura-se claro que as instituições de I\&D estão a assumir impactos positivos nas empresas que com elas cooperam.

Em termos gerais parece ser possível concluir que as empresas mais activas, inovadoras e competitivas, que revelam maiores preocupações em termos de mercado, tendem a recorrer às valências dos centros de I\&D.

As relações com instituições de I\&D afiguram-se como fazendo parte de uma estratégia mais global de aquisição de competências tecnológicas e humanas por parte dessas empresas.

Porém, apesar das correlações positivas entre a existência de contactos com centros de I\&D e os comportamentos inovadores e competitivos por parte das empresas, pode concluir-se que apenas um número limitado de empresas acede às vantagens decorrentes dessa ligação.

As entrevistas realizadas nas IC\&T evidenciam a preferência destas instituições em estabelecerem relações privilegiadas com grandes empresas, quer nacionais quer estrangeiras.

As ligações que as IC\&T mantêm com as pequenas empresas características do tecido empresarial português, assentam essencialmente em actividades de certificação, teste, etc.. A actividade de investigação tende a ser realizada apenas com grandes empresas. As razões para tal realidade encontram-se no facto das pequenas empresas não apresentarem condições para solicitar apoio tecnológico e científico muito avançado (ou por considerarem não necessitar dele, ou por não 
deterem as condições humanas e financeiras para o requerer/realizar). Tendencialmente são as grandes empresas, nomeadamente internacionais, que reúnem as condições necessárias para solicitar, e também acompanhar, desenvolver e aproveitar o conhecimento produzido. Estas empresas detêm os interlocutores preparados para participar nos projectos (em muitos casos financiados pelas próprias empresas) e assumem o seu envolvimento com expectativas quanto ao potencial valor acrescentado que deles poderá advir.

\section{A RELAÇÃo ENTRE IC\&T E EMPRESAS - LIMITAÇões E CONDI ÇÕES DE SUPORTE}

\subsection{Tipo de solicitação científica e tecnológica}

As opções tecnológicas das empresas portuguesas são bastante determinadas pela facilidade percebida na importação e na imitação das tendências de outras empresas. Tal facto explica a fraca importância que as empresas atribuem ao desenvolvimento endógeno de tecnologia, e a reduzida apetência para procurarem as valências das IC\&T. Mesmo que os técnicos sejam sensíveis às questões da inovação e da investigação, nem sempre os empresários o são também, preferindo copiar ou adquirir tecnologia no estrangeiro.

A fraca base tecnológica das empresas leva a que estas tendam a fazer mais desenvolvimento e requeiram mais actividades de consultoria do que investigação. Os resultados das actividades científicas e tecnológicas passíveis de serem executadas com a maior parte das empresas portuguesas não são por isso publicáveis em revistas científicas, o que colide com as necessidades de algumas IC\&T mais próximas da universidade.

O facto do desenvolvimento de actividades de I\&D deter um elevado risco associado, demove a realização desse tipo de investimento, e a aceitação de opções que possam colidir com as tecnologias instaladas, mesmo que estas evidenciem problemas ou possam ser melhoradas.

Verificam-se casos em que as empresas acedem a colaborar em projectos de investigação apenas porque tal lhes é solicitado. Como não detêm uma verdadeira motivação quanto aos resultados dos projectos, e nem sempre investem os recursos previstos, esta situação salda-se no desinteresse e em atrasos na realização de actividades sob a sua responsabilidade. Embora o desinteresse das empresas 
possa ser justificado pela excessiva sofisticação tecnológica dos projectos, verificam-se situações em que as empresas estrangeiras envolvidas utilizam os resultados, ao invés das portuguesas.

A diferença de patamares das empresas portuguesas e das IC\&T em termos de conhecimento é evidente, potenciando a desarticulação das expectativas de ambas as partes.

Contudo, o desajustamento da investigação levada a cabo pelas IC\&T pode ler-se a dois níveis: existem projectos cujos resultados não são aplicáveis à realidade portuguesa, porque a investigação é realizada a um nível de conhecimento excessivamente elevado; os resultados dos projectos não são aplicados porque existe uma base de conhecimento insuficiente do lado da indústria. A inversão deste desfasamento implicaria um up-grade por parte da indústria ou a regressão no conhecimento produzido pelas IC\&T.

Apesar destas dificuldades de parte a parte, algumas IC\&T mais próximas da universidade consideram existir potencial para a transferência dos saberes que geram para o tecido empresarial português, numa assunção de desarticulações que não são explicadas por desnivelamentos nas bases de conhecimento. Tais insuficiências poderão ser explicadas pelas condições de partida do SCT e pela génese das IC\&T no que se refere à sua concepção e gestão. A lógica linear que esteve latente na constituição das IC\&T, e o facto destas terem sido baseadas no trabalho de actores com estratégias e expectativas diversas, potenciou uma desarticulação que já de si tende a existir. As empresas também não se sentem estimuladas a ultrapassar essa insuficiência.

Para além dos aspectos referidos anteriormente, a reduzida ligação que se identifica entre sector produtivo e instituições de I\&D pode ser explicada por factores de ordem cultural, nomeadamente pela dificuldade nacional em lidar com situações de incerteza (Hofstede, 1997), e pela forma negativa como se encaram as situações de maior ambiguidade.

A actividade de I\&D tem inerentes fortes riscos quanto aos resultados das actividades realizadas. O facto das empresas nem sempre conseguirem definir claramente o que pretendem, o receio de obterem produtos finais que não correspondem às suas necessidades, a falta de consciência quanto à missão e condições de funcionamento das IC\&T, conduz a uma rejeição de investimentos cujos resultados sejam incertos.

A relação com empresas multinacionais instaladas no país poderá configurar-se como uma alternativa para as IC\&T, com potenciais efeitos miméticos. Contudo, muitas empresas são pertença de grupos 
que promovem as actividades de I\&D noutro local ${ }^{14}$. Para empresas que pertencem a grandes grupos mundiais que utilizam tecnologia patenteada (exclusivamente desenvolvida nos seus laboratórios), o recurso a IC\&T não só se afigura desnecessário como implicaria eventuais riscos de transferência de conhecimento. Outras empresas não recorrem aos recursos existentes no país pelo facto de não reconhecerem o seu valor, ou porque nem sempre existem as competências necessárias para desenvolver o tipo de tecnologia que utilizam.

\subsection{Diferenciais na expectativas e necessidades institucionais}

Vários têm sido os limites identificados nas relações entre as universidades e o sector empresarial, decorrentes de objectivos, lógicas de funcionamento e necessidades distintas.

Algumas empresas expressaram uma imagem negativa dos investigadores, pelo seu excessivo academismo, pela sua tendência para teorizarem independentemente das condições reais de partida, pelo seu perfeccionismo. Estas imagens foram justificadas quer pelos contactos estabelecidos quer pelas experiências pessoais de formação académica.

Outro dos antagonismos evidentes prende-se com a questão dos prazos e dos tempos, problema que a indústria vive com grande acuidade pelos riscos de perda de oportunidades que um atraso pode gerar. Os universitários podem ver o tempo de forma mais difusa, pelo facto de estarem envolvidos num processo de produção e melhoria do conhecimento. Enquanto os investigadores tendem a analisar as situações centrados na sua melhoria a médio ou mesmo longo prazo, as empresas tendem a preocupar-se com as actividades e melhorias numa lógica mais imediata. ${ }^{15}$

O quadro de interacções entre empresas e IC\&T é bastante recente, sendo evidentes os percursos que as instituições terão que realizar para conseguirem maximizar os recursos disponíveis e estimularem a emergência de cadeias de geração de competências.

A reactividade das empresas em termos tecnológicos, bem como a sua dependência de incentivos, espraia-se às relações com as IC\&T e à realização de actividades de I\&D. Apesar dos projectos de investigação poderem contribuir para resolver problemas das empresas, estas tendem a avançar apenas quando há garantia de financiamento. Estas situações reflectem-se no funcionamento das

\footnotetext{
${ }^{14}$ Verificam-se casos em que as empresas multinacionais recorrem a IC\&T pontualmente por questões mais comerciais do que científicas e tecnológicas (por exemplo para poderem publicitar os resultados de testes).

${ }^{15} \mathrm{O}$ desconhecimento das exigências colocadas à função docente e de investigação podem também conduzir a expectativas irrealistas face às actividades que devem ser desenvolvidas e ao tempo que estas podem requerer.
} 
próprias IC\&T, dado que os atrasos na avaliação dos projectos e a ausência de compromisso por parte das empresas, conduzem por vezes ao envolvimento dos investigadores noutras actividades e a uma menor disponibilidade se os projectos são entretanto aprovados.

Para além destes constrangimentos relacionados com as condições de produção e aplicação do conhecimento, existem questões relacionadas com a forma como as instituições se posicionam num quadro mais vasto de relações e interacções sociais.

A produção, a disseminação e a integração do conhecimento são estabelecidas com base num conjunto de relações de carácter científico e tecnológico, enquadradas pelas normas e valores subjacentes às relações entre actores sociais.

A sociedade portuguesa foi e continua a ser marcada por relações elitistas e desnivelantes, em que a posse do conhecimento tradicionalmente detido por uma classe minoritária, dificulta o desenvolvimento de relações complementares entre vários agentes sociais.

Muitas empresas são detidas por empresários com formação escolar muito reduzida, que nem sempre possuem as ferramentas conceptuais e psicológicas que lhes permitem estabelecer contactos com universidades e instituições de I\&D. Por vezes apresentam mesmo uma atitude negativa face a essas fontes de saber.

\subsubsection{A utilização do conhecimento}

A propriedade intelectual tende a ser considerada uma das questões delicadas na relação entre instituições de I\&D e empresas.

A importância da publicação para a academia e a necessidade de segredo industrial por parte das empresas tem sido avançada como uma das origens das tensões entre ambos os tipos de instituições.

Verifica-se porém que esta tensão é mais pontual do que permanente. Os investigadores e empresas inquiridos tendem a considerar que a publicação é possível sem pôr em causa o segredo industrial (sendo prática sujeitar à apreciação das empresas os artigos que se pretendem publicar). Não é necessariamente o segredo industrial que está em causa na rejeição das publicações: numa situação 
concreta, esta decorreu do desejo de evitar a conclusão de que o produto da empresa tivera que ser melhorado.

Verificou-se mesmo que a publicação conjunta entre investigadores próprios e de IC\&T é apreciada por algumas empresas, como forma de valorizar a sua imagem.

A propriedade intelectual parece ser mais problemática no que se refere ao reconhecimento do autor e da extensão do conhecimento produzido.

Alguns IC referem a sua tendência para estabelecerem contratos muito gerais (ou quase verbais), firmados pelos investigadores, que têm conduzido a um aproveitamento por parte de empresas no que se refere à amplitude das actividades exigidas. São também várias as situações de IC que referem não ter salvaguardado o seu envolvimento em projectos, por excesso de confiança ou desconhecimento dos termos em que os contratos deveriam ser realizados, não lhes sendo reconhecido o seu envolvimento aquando da comercialização do produto/processo.

Nos casos das restantes IT, que tendem a desenvolver núcleos de apoio à realização de contratos, tais problemas não se colocam com a mesma acuidade. São também as empresas que recorrem de forma mais sistemática às IC\&T que reflectem uma maior tendência para formalizarem em contrato todas as condições da relação estabelecida, e referem não ter problemas a esse nível, num reflexo claro das relações de aprendizagem inter-organizacional necessárias a esta relação.

\subsubsection{A praxis cientifica e empresarial e a empatia institucional}

As diferenças de objectivos e condições de partida em que se encontram empresas e IC\&T, e as exigências subjacentes à sua interacção, pressupõem a existência de condições em ambas as partes que permitam sustentar tal interacção.

Do lado das IC\&T, essas condições passam pela existência de investigadores identificados com a sua missão e sensibilizados para as necessidades das empresas. Do lado das empresas, tornam-se necessários recursos associados à integração do conhecimento, o que pressupõe a sua produção endógena, e o domínio de códigos que permitam perceber o discurso, as expectativas e necessidades da outra parte. 
O facto das empresas apresentarem pequenas estruturas organizacionais, a escassez de pessoas com competências técnicas de nível superior dificulta o aproveitamento dos conhecimentos disponíveis. Alguns processos mais complexos requerem que as empresas possuam um núcleo responsável pela I\&D com capacidade e com tempo para reflectir sobre eles. A incapacidade de aproveitar o conhecimento decorre muitas vezes das várias solicitações a que os colaboradores das empresas são sujeitos, sendo a sua prioridade responder a questões imediatas de produção.

Um das críticas evidentes ao trabalho das IC\&T mais próximas da universidade é o facto de se considerar que estas falham no desenvolvimento dos produtos, e terminam antes de todo o processo estar assegurado. Por não possuírem os seus próprios meios de desenvolvimento, as empresas esperam que sejam as instituições de I\&D a assegurar esse tipo de actividade, embora a missão destas instituições pressuponha um trabalho científica e tecnologicamente mais complexo.

O facto das empresas nem sempre terem claro o que pretendem (indefinição que se revela na aprovação dos projectos e nas decisões quanto à sua evolução), o facto das IC\&T não compreenderem a lógica própria ao funcionamento das empresas, leva a que as relações sejam muitas vezes estabelecidas assumindo a compreensão do que é pretendido pela outra parte, algo que nem sempre é corrigido através de posteriores contactos regulares.

A incapacidade de aproveitar os resultados de uma investigação pode decorrer da própria dinâmica dos mercados. Estes podem sofrer alterações nas condições de utilização de um determinado resultado ou nos requisitos necessários para a sua rentabilidade, num exemplo claro das pressões que o tempo gera para o sector empresarial.

A investigação é uma prática caracterizada pela incerteza. Nas relações estabelecidas nem sempre se clarifica a existência desta incerteza, o que justifica posteriores mal-entendidos que por vezes se reflectem negativamente nas relações entre instituições. Uma vez mais se denota que são as empresas que desenvolvem actividades de I\&D que melhor apreendem os pressupostos desta relação, tendendo a centrar-se mais no respeito por prazos de análise de um problema, do que na expectativa quanto a resultados concretos.

Parte das dificuldades de relacionamento entre IC\&T e empresas pode ser explicada pela incompreensão da práxis específica de cada tipo de instituição, da incapacidade de realizar os constrangimentos e condições de aç̧ão de cada uma, e da criação de expectativas irrealistas que podem redundar em generalizações limitadoras de posteriores relações de cooperação. 
Da parte das empresas, a ausência de uma práxis científica, adquirível através do desenvolvimento interno de actividades de I\&D ou pela experiência de investigação de colaboradores, faz com que estas desconheçam as características e dinâmica próprias dos processos de investigação. Acrescem atitudes de algum utilitarismo quanto à função das universidades, que colidem com as funções que estas devem reservar para si.

Da parte das IC\&T a ausência de uma práxis empresarial decorre da escassez de contactos com as empresas e de experiências empresariais, levando ao desconhecimento dos constrangimentos em que estas operam. A própria lógica de gestão de várias IC\&T, ancorada por exemplo em suportes financeiros externos, leva a que nem sempre seja muito relevante a eficácia da sua gestão, mas a qualidade da sua produção.

Verifica-se que as relações mais frutuosas se estabelecem entre interlocutores sensíveis à praxis específica do seu interlocutor. Tal sensibilidade permite a compreensão das lógicas, constrangimentos e requisitos da outra parte, desenvolvendo uma empatia institucional que sustenta comportamentos potenciadores de relações eficazes.

\section{QUE I NFLUÊNCI A NA CONSI STÊNCI A DO SNI ?}

\subsection{A complementaridade das IC\&T numa rede científica e tecnológica nacional - uma expectativa adiada}

Os programas CIENCIA e PEDIP foram desenhados assumindo que as instituições a constituir se deveriam complementar e estabelecer interacções sinérgicas no espaço científico e tecnológico nacional.

Os incentivos atribuídos aos IC tiveram subjacente uma lógica de criação de massa crítica e de redes de geração de conhecimento. Estimulou-se a agregação de grupos por áreas de interesse (e não em função de áreas disciplinares). Se o pressuposto de origem quanto às vantagens de criar massa crítica não estava incorrecto, tornava-se necessário que as instituições se sentissem estimuladas para manter essas redes. 
O que se verifica actualmente é que a maioria das instituições multi-polares se estão a autonomizar. A dificuldade em realizar uma actividade de investigação em parceria com instituições geograficamente distantes foi uma das justificações para a progressiva autonomização dos pólos e para a escassez de relações que mantêm entre si. Verifica-se porém que as instituições se encontram envolvidas em várias parcerias internacionais, em relação às quais os constrangimentos geográficos serão mais evidentes.

A colaboração entre instituições situadas no espaço nacional pressuporia por isso a criação de estímulos para esse tipo de prática, de forma a que esta se afigurasse estratégica para a sua sobrevivência. Tais ligações são dificultadas num quadro em que os pólos concorrem entre si pelo acesso a recursos escassos, e onde as cooperações internacionais são relevantes para os processos de aprovação de projectos.

As IT foram perspectivadas mais próximas do "pólo da ciência" ou mais próximas do "pólo do mercado”, procurando a cobertura de um continuum de necessidades científicas e tecnológicas. Denotam-se apenas algumas práticas pontuais de colaboração, por exemplo de partilha de equipamento.

Um dos traços marcantes da génese das IC\&T em Portugal foi a forma como as opções de investimento em termos de infra-estruturas físicas e de equipamentos foram assumidas.

Verifica-se que a partilha de equipamentos é algo de bastante pontual, sendo ainda mais raras as referências a uma aquisição concertada. A partilha é possível quando há grande proximidade das instituições ou quando elas estão perto da universidade. Mesmo no caso dos IC multi-polares, a complementaridade na aquisição de equipamentos foi conseguida em casos raros. O que se verificou foram duplicações na sua aquisição, que nalguns casos resultaram numa baixa taxa de utilização dos mesmos ou mesmo na sua não utilização. Se em certas áreas a partilha de equipamento pode ser dificultada, também poderá existir alguma incapacidade em aceitar a necessidade de a realizar.

A esta situação estão subjacentes diferentes tipos de explicações.

O facto das instituições deterem uma massa crítica insuficiente implica que a aquisição de certos equipamentos implique inevitavelmente a sua sub-utilização, sob pena de certo tipo de investigação não poder ser realizada por esses grupos e redunde numa quebra de qualidade. 
Outra razão é a dificuldade de partilhar meios quando a distância geográfica é significativa, embora este seja um constrangimento variável em função das disciplinas científicas e das actividades realizadas.

Acrescem ainda constrangimentos relacionados com a operação de equipamentos, por vezes muito sofisticados, e que carecem de utilizadores especializados.

No caso das IT, a aquisição de equipamentos deu muitas vezes resposta ao que era necessário para desenvolver a investigação universitária e não para responder às reais necessidades da indústria (fosse por desconhecimento da realidade desta, fosse por um desajustamento na forma como a missão destas instituições era encarada).

A desadequada aquisição de equipamentos decorreu igualmente de uma deficiente avaliação da procura, tendo algumas instituições criado expectativas sobre a evolução das empresas nacionais, por via dos efeitos dos fundos de coesão, que nunca se chegaram a verificar.

O sub-aproveitamento de recursos verificado em todos os tipos de IC\&T também é explicável pelo facto da sofisticação do equipamento ter constituído um símbolo da qualidade da instituição/grupo/investigador e ser utilizado como um meio de afirmação perante os pares e perante o exterior.

A facilidade relativa de acesso a fundos conduziu à aquisição acrítica de equipamentos e de espaços, que posteriormente se saldou em profundas dificuldades de auto-financiamento, na necessidade de desactivar áreas cuja rendibilidade não tinha sido previamente assegurada e no aluguer de espaços como forma de garantir a sobrevivência das instituições.

A complementaridade entre as instituições pode ser visível também pela forma como estas se assumem num continuum de geração de conhecimento. Como foi referido, em alguns casos de sucesso esta complementaridade é bem evidente, pelo facto das instituições se assumirem interligadas numa lógica de especialização.

Não se verificou que este tipo de complementaridade se estendesse às restantes IC\&T. No caso de um IC e de um INT da mesma área disciplinar e associados à mesma Universidade, as tentativas de associação foram mesmo goradas, devido à resistência dos investigadores do IC. 


\title{
11.2. Desnivelamento das plataformas do conhecimento de base - investigação centrada no país ou com perfil internacional?
}

\begin{abstract}
Algumas críticas que são realizadas à investigação das instituições mais próximas da universidade prendem-se com a escassez de resultados industrialmente aplicáveis. Em certas áreas de investigação não existem sequer em Portugal empresas que possam aplicar os resultados obtidos.
\end{abstract}

Verifica-se por isso a situação algo paradoxal das IC\&T terem sido criadas para suportar a indústria portuguesa mas estarem de facto a desenvolver actividades que apoiam empresas de outros países.

A própria lógica de financiamento da investigação realizada no país potencia os contactos com empresas estrangeiras. São os projectos europeus, pelos montantes envolvidos e pelo tipo de conhecimento a desenvolver, que sustentam a realização de investigação de qualidade. Os financiamentos nacionais dificilmente permitem promover investigação mais continuada, pela limitação dos montantes envolvidos.

A questão que se pode colocar é se as IC\&T deveriam realizar um reajustamento nas actividades realizadas por forma a efectivamente apoiarem as necessidades tecnológicas das empresas portuguesas.

O ajustamento do conhecimento produzido constituiria uma regressão, dado que ele seria produzido tendo como padrão uma realidade empresarial que revela deficiências quanto à "qualidade” do conhecimento que mobiliza, o qual se afigura insuficiente no quadro de uma Economia da aprendizagem. O esforço deverá por isso colocar-se mais na identificação dos factores que permitirão uma melhor utilização dos recursos disponíveis, aproveitando o potencial de colaboração entre empresas e instituições de I\&D.

É também evidente que as colaborações internacionais apresentam efeitos benéficos para a criação de cadeias de geração de competências.

Todas as instituições referem a importância de desenvolver investigação em parceria com grupos internacionais, pela oportunidade de aquisição de novos conhecimentos que tais consórcios representam (e que tendem a manter-se e a evoluir para redes privilegiadas), e pelas oportunidades decorrentes das relações com parceiros fortes. Para algumas instituições a participação em projectos 
europeus constitui, inclusive, uma oportunidade de perceber evoluções possíveis nas áreas onde actuam e determinar algumas opções de investimento.

Constituindo à partida uma excelente oportunidade para adquirir conhecimentos relevantes, os projectos europeus saldam-se por vezes em relações conflituantes, decorrentes de estratégias institucionais e de pressupostos sobre a competência dos vários parceiros.

Algumas empresas inquiridas, com recursos tecnológicos e financeiros mais limitados, referiram situações em que informação fundamental desenvolvida no decurso do projecto é escamoteada. Estas empresas ficam impossibilitadas de a obter pelo facto de não possuírem recursos financeiros, ou por não terem estado envolvidas na sua produção.

Também se colocam questões relacionadas com a propriedade intelectual, dado que se denotam problemas quanto à paternidade de actividades realizadas.

Por vezes as relações das instituições estrangeiras com as portuguesas são dúbias e motivadas apenas pelas maiores facilidades de aprovação dos projectos devido ao carácter periférico do país. Tal realidade traduz-se em formas de cooperação marcadas por expectativas negativas e desconfiança face às qualidades intrínsecas das instituições (sejam empresas ou IC\&T), que se estendem a todo o processo de colaboração.

Para algumas empresas inquiridas, que referem a dificuldade de penetração em mercados externos devido a uma história de atraso empresarial, cultural e social (que criou uma má imagem da tecnologia portuguesa), a integração em projectos europeus é encarada não só como uma oportunidade para obter novo conhecimento, mas também como uma forma de imprimir um rumo mais favorável aos contactos comerciais. No limite, tais práticas ajudarão a alterar a disposição dos portugueses face ao estrangeiro e de alterar a imagem do país no exterior.

\subsection{A avaliação externa como forma de correcção de trajectórias}

As instituições promovidas no âmbito dos programas PEDIP têm sido objecto de algumas tentativas de avaliação e uniformização de critérios, mas bastante pontuais, até pela própria lógica de funcionamento das instituições. Os esforços de avaliação têm sido efectuados ex-ante, aquando da apresentação de candidaturas, ou através do acompanhamento institucional, mas sem um modelo ou indicadores estabelecidos. 
Os IC (tal como as restantes unidades financiadas pelo MCT) estão sujeitos a um processo de avaliação contínuo, no âmbito do Programa de Financiamento Plurianual de Unidades de I\&D.

Esta avaliação tem impactos em dois tipos de financiamentos: o Financiamento de Base (dependente do número de investigadores doutorados e da classificação obtida pelas actividades científicas), e o Financiamento Programático Especial (atribuído para responder a necessidades específicas, sob sugestão dos painéis de avaliadores).

A metodologia de avaliação, através de peer review, assenta na interacção directa com representantes das unidades de investigação, através de visitas ou em sessões de apresentação das actividades da unidade em questão.

A apreciação dos painéis de avaliação suporta-se também na análise documental, tendo por base critérios como a qualidade e quantidade dos resultados atendendo ao número de doutorados, a relevância da actividade de investigação, a qualidade e quantidade da internacionalização. Na visita à instituição ou na sessão de apresentação pretende-se avaliar o mérito intrínseco das actividades da unidade, a organização e ambiente de trabalho, e os recursos da unidade de investigação.

A prática de avaliação dos IC teve impactos significativos no funcionamento destas instituições.

Sendo um processo de aferição de qualidades individuais e institucionais, a avaliação tem inerente uma potencial conflitualidade, decorrente dos impactos psicológicos (e efectivos) que um resultado menos positivo pode assumir para os avaliados.

A estes impactos, acresce o facto da avaliação ser um processo baseado em interacções, por isso permeável à subjectividade, quer pela informação prévia sobre a instituição/interlocutor, quer pela própria dinâmica da relação face a face (Hadji, 1994).

Vários limites têm sido identificados quanto à forma como o processo de avaliação dos IC é conduzido, considerando-se que os critérios de avaliação não são completamente claros, nomeadamente quando se comparam os resultados obtidos pelas várias instituições. A conflitualidade subjacente a este processo é expressa na forma como as classificações menos positivas tendem a ser justificadas, por “questões políticas” relacionadas com a pertença dos avaliadores. 
Um aspecto identificado prende-se com a desadequação das equipas, que nem sempre recobrem as áreas disciplinares presentes numa instituição.

Também a escassez da duração das visitas para apreciar todo o funcionamento da organização é apontada como um limite. Este torna-se especialmente negativo porque a apreciação pressupõe a expressão sobre aspectos tão complexos e sensíveis como a organização e a liderança internas à organização.

Finalmente surgem críticas pelo facto das equipas de avaliação poderem ter como quadros de referência realidades científicas completamente distintas das nacionais.

É evidente que a rejeição das metodologias de avaliação pode constituir uma oportunidade para reduzir a dissonância cognitiva ${ }^{16}$ decorrente de uma apreciação menos positiva, e de justificar, externa e internamente, os resultados obtidos.

O sentimento de injustiça associado a alguns resultados poderá ter também na origem o facto das instituições não terem interiorizado uma cultura de avaliação e não se prepararem para esse processo de forma estratégica.

A qualidade da avaliação dos IC poderá ser questionada pela subjectividade imanente aos processos de avaliação e pela forma como estes são materializados. É porém evidente que este modelo de avaliação está construído para medir o que pretende medir: a qualidade da investigação científica produzida.

A avaliação dos IC, tal como tem sido realizada, permite posicionar a investigação nacional face a padrões de comparação internacional. Esta opção afigura-se especialmente adequada se se considerar que, numa lógica de excelência, a avaliação não se deverá centrar numa prática normativa, que compare os grupos nacionais entre si, mas posicioná-los face a padrões de nível internacional. A avaliação permitirá assim determinar o caminho que falta percorrer e os meios que ainda deverão ser reunidos.

Porém, mesmo que os equipamentos se igualem aos existentes nos países cientificamente mais desenvolvidos, os resultados obtidos em termos de I\&D decorrem de outros factores. Para além da qualidade dos RH envolvidos, o resultado final é moldado por todo um conjunto de condições de

${ }^{16}$ Necessidade de encontrar congruência e equilíbrio entre os nossos actos e cognições. 
suporte que incluem aspectos de natureza administrativa e logística, recursos humanos, instituições de I\&D inter-relacionadas e instituições financiadoras. A avaliação poderá por isso penalizar as instituições por resultados que são parcialmente explicados pelo contexto mais global em que estas se inserem.

A forma como as IC\&T são avaliadas permite concluir que se está ainda perante um processo incipiente de aferição dos seus contributos económicos e sociais. São evidentes os factores subjectivos associados à avaliação através de peer review e a amplitude e “fluidez" de aspectos que é suposto as equipas de avaliação apreciarem. A estabilização de alguns indicadores qualitativos e quantitativos, que recubram o modelo de instituição desejado e a sua dinâmica num quadro global de complementaridade das instituições, pode permitir que os processos de avaliação ajudem a criar as sinergias necessárias a um SNI. Se se definirem apenas princípios de avaliação, fica-se mais sujeito à subjectividade dos avaliadores e aos seus quadros de referência.

A definição de tal modelo de avaliação das IC\&T pressupõe igualmente que IT e IC deixem de ser encarados de forma autónoma e desconexa, para serem encaradas quanto à sua missão de geração de competências no espaço nacional.

Pressupõe também que a função das instituições e a sua complementaridade institucional seja estabelecida, por forma a poder definir os padrões de tal apreciação. Na RCM n¹33/97 o Ministério da Ciência e Tecnologia foi incumbido de estabelecer o quadro normativo aplicável às instituições que se dedicam à actividade científica e ao desenvolvimento tecnológico (o que se veio a efectuar através do DL nº 125/99).

Este DL define as formas e critérios de acompanhamento e avaliação e as orientações gerais para a disseminação da cultura científica e tecnológica para os Laboratórios de Estado, para os Laboratórios Associados, tal como para “outras instituições públicas de investigação”. Nos critérios de avaliação incluem-se, entre outros: "os resultados e o sucesso da actividade científica ou tecnológica desenvolvida (...)" e os "resultados e o sucesso obtidos com a prestação de serviços a entidades externas, públicas ou privadas, e com actividades de certificação, normalização, regulamentação, peritagens e outras, bem como a eficiência da instituição na obtenção desses resultados”. Verifica-se assim que todas as instituições "podem desenvolver todas as actividades". 


\section{A GÉNESE DAS ICQT COMO LIMITE PARA A CONSISTÊNCIA DO SNI - ALGUMAS NOTAS CONCLUSIVAS}

A capacidade de medir os impactos das actividades desenvolvidas pelas IC\&T continua em aberto, dado o carácter transversal e os efeitos multiplicadores que a geração e a utilização do conhecimento assumem.

Não sendo objectivo deste trabalho uma análise quantitativa destes impactos, considera-se porém a necessidade de avaliar o retorno dos investimentos realizados, nomeadamente por questões de financiamento e redefinição de trajectórias em termos de política científica e tecnológica.

Com base nos dados recolhidos, é possível concluir que as IC\&T estão a assumir impactos no SCT, porque a sua actividade de investigação e de formação de recursos humanos permite construir as bases necessárias ao estabelecimento progressivo de redes de geração de competências.

A actividade científica e tecnológica das IC\&T contribui para alargar a profundidade do conhecimento disponível interna e externamente, permitindo melhorar as lógicas de análise e de resolução de problemas e a capacidade de intervenção dos detentores desse conhecimento.

Ao promoverem a formação de recursos humanos e ao contribuírem para o acréscimo de conhecimento da população activa (e da população em geral), as IC\&T estão a estimular a geração de competências que constituem pré-requisitos do desenvolvimento económico (Kim, Nelson, 2000). A formação é determinante para a qualidade das actividades realizadas mas também para situar e compreender a oferta existente nas instituições produtoras de saber.

Quando as IC\&T resolvem problemas tecnológicos, desenvolvem projectos de I\&D em parceria com empresas, quando permitem que empresas portuguesas acedam a fontes de conhecimento externas, estão a estimular a geração de competências.

É porém evidente que as IC\&T estimulam a geração de competências a um ritmo mais lento do que seria desejável e possível, mesmo atendendo à sua juventude e à ausência de um processo prévio de aprendizagem da missão e valências destas instituições por parte dos agentes do SCT.

As razões para a desarticulação encontrada serão várias. 
A desarticulação verificada entre os agentes do SCT denota-se na forma como a missão das várias instituições de I\&D é encarada, e na dificuldade em compatibilizar as actividades a realizar no âmbito de cada uma delas. O programa PEDIP e o programa CIENCIA foram desenvolvidos de forma autónoma, e a posterior evolução em termos de política científica e tecnológica manteve esta desarticulação.

Outras razões prendem-se com o perfil das empresas nacionais.

Apesar da inversão verificada na especialização produtiva do país no decurso dos anos 90, ainda é notório o peso das indústrias com carácter tradicional, cuja competitividade continua a basear-se predominantemente no factor custo. As empresas não são impelidas a identificar e a procurar factores de competitividade assentes no desenvolvimento de actividades de I\&D. O tipo de especialização produtiva leva a que as empresas sejam "efectivamente auto-suficientes” e respondam a todas as suas necessidades, dado o tipo de actividade e de tecnologia que utilizam.

O facto das IC\&T terem uma origem muito recente, não permitiu ainda a criação de sinergias e de uma prática mais generalizada de aquisição dos serviços prestados por estas instituições. A própria "necessidade" das IC\&T não se tornou evidente para as empresas, decorreu mais de condições e condicionalismos externos. A disponibilidade de fundos não tornou premente a realização de opções de investimento. Tal situação redundou numa duplicação parcial de instituições, com os inevitáveis problemas de sustentação num mercado escasso.

O facto das instituições terem sido criadas numa lógica linear que permitiu a sua duplicação, facilita distorções em termos de mercado (face aos seus objectivos), no sentido em que as que concorrem com empresas apresentam melhores condições de sobrevivência. Algumas instituições sobrevivem do aluguer dos seus espaços, da promoção de formação financiada, ou de dumping em actividades de cariz processual. Outras, pelo desejo de iniciar contactos com os clientes, ou pelas suas dificuldades financeiras, "aproveitam tudo".

Esta concorrência dúbia pode contribuir também para habituar as empresas a pagar os serviços científicos e tecnológicos abaixo do preço de mercado. Tal situação agrava um quadro já de si marcado pela importância do suporte externo no desenvolvimento de actividades das empresas, por alguma atitude de dependência face a subsídios e incentivos, e pela falta de responsabilidade própria na realização dos investimentos quando estes se revestem de incerteza. 
Há de facto uma triagem das IC\&T através do mercado, mas em muitos casos esta é efectuada à custa do desvirtuamento da missão destas instituições.

Acresce a génese das IC\&T, ocorrida num quadro marcado pela escassez de competências científicas e técnicas nas áreas da sua implantação, que conduziu à criação de certas instituições segundo lógicas essencialmente vantajosas para as universidades, potenciando o desvirtuamento da sua missão. Tais modelos de organização, em que avulta a ausência de recursos humanos próprios e permanentes, poderão ajudar a explicar a maior dificuldade das IC\&T portuguesas se posicionarem no mercado com as suas reais valências tecnológicas, paralelamente a um número de potenciais utilizadores já de si escasso.

A “colagem" ao sector universitário foi problemática porque há uma clara autonomia entre os objectivos e a lógica de gestão das universidades e os objectivos das IC\&T. É evidente a dimensão antagónica entre a necessidade de promover projectos integradores, de desenvolver actividades de cooperação empresarial e o individualismo preconizado pelo estatuto da carreira académica. Desenvolveu-se um sistema assente nos pressupostos de funcionamento e de gestão de um outro sistema, sem que ambos tivessem sido ajustados.

Sendo difícil e indesejável autonomizar IC\&T e universidades, afigura-se necessário definir um modelo que, salvaguardando as especificidades e lógicas internas das instituições, as posicione como agentes complementares num sistema de geração de competências, definindo modalidades de avaliação e financiamento que permitam corrigir as práticas instituídas.

A fragilidade que muitas IC\&T apresentam em termos de gestão é também evidente. As situações de sucesso encontram-se nas instituições que conseguiram criar o seu espaço (no mercado nacional e/ou internacional), ajustando-se às condições oferecidas pela envolvente, e desenhando configurações e modalidades de organização internas adaptadas a essa envolvente.

De que forma o caso português se distingue quanto ao papel que as IC\&T ocupam na construção de um SNI?

Os dados identificados permitem concluir pela existência dos mesmos problemas de desarticulação que se encontram em vários outros países, nomeadamente naqueles em que a constituição de IC\&T não resultou de pressões explícitas e de necessidades bem definidas pelos sectores industriais (Rush, Howard et al. 1996). A importância que as pressões e dinâmicas endógenas aos sectores e empresas assumem para os resultados das IC\&T pode ser encontrada, embora que a título modesto, em alguns 
CT: quando estes foram constituídos por iniciativa de sectores e empresas, e não como resultado da disponibilidade de incentivos, as situações de sucesso em termos de exploração e de ligação aos potenciais utilizadores é mais evidente.

As pressões criadas pelas exigências do mercado afiguram-se igualmente relevantes para o estabelecimento de relações de cooperação entre IC\&T e empresas. Embora não se encontre uma associação entre grau de concorrência sentido pelas empresas inquiridas e a sua apetência para promover tais ligações (a maioria das respostas dão conta de um acréscimo da concorrência nos últimos anos), verifica-se que as atitudes mais pro-activas em termos de posicionamento no mercado potenciam o aproveitamento da capacidade instalada nas IC\&T (por exemplo são as empresas certificadas e que possuem produtos certificados que mais tendem a estabelecer essas ligações).

Os dados obtidos através do inquérito permitem concluir que existência de capital estrangeiro assume influência no posicionamento das empresas face ao desenvolvimento de actividades de I\&D. O facto das empresas com capital totalmente nacional ou estrangeiro tenderem a desenvolver menos actividades de I\&D será a expressão das estratégias de localização das empresas multinacionais e das lógicas de gestão e de investimento das empresas nacionais: no caso das empresas multinacionais, verificar-se-ão as tendências para usufruir das vantagens que uma mão de obra desqualificada e barata ainda podem representar, sem que exista um investimento em actividades de valor acrescentado (leia-se I\&D) em termos produtivos; no caso das empresas com capital totalmente nacional estarão em causa prováveis lógicas de investimento imitativas, centradas no curto prazo e determinadas predominantemente pelo factor custo. $\mathrm{O}$ facto das empresas com maiores níveis de I\&D deterem capital simultaneamente nacional e estrangeiro, poderá traduzir a influência de lógicas de gestão em que a I\&D e o aproveitamento da capacidade instalada no país são encaradas como factor de diferenciação.

A escassez de relações de cooperação face ao potencial de investigação instalado nas IC\&T e a dificuldade destas se assumirem como um valor acrescentado para as empresas é clara, apesar da colaboração com IC\&T se encontrar associada a melhores resultados em termos competitivos.

As dificuldades de relacionamento com as empresas são potenciadas no caso português pela especificidade e configuração do tecido empresarial e da génese das IC\&T. O predomínio de micro e pequenas empresas em sectores tradicionais, que recorrem escassamente à I\&D como factor de inovação a nível de processos e produtos, a ausência de grandes empresas de cariz internacional em áreas tecnologicamente evoluídas, permitem a configuração de um quadro que desincentiva tais relações. O facto das empresas apresentarem uma dimensão reduzida e a sua fraca capacidade para 
desenvolver internamente actividades de I\&D poderia constituir à partida um factor incentivador para o estabelecimento de tais relações de cooperação. O desfasamento das bases de conhecimento disponíveis nas empresas e nas IC\&T, evidentes num país caracterizado pela escassez da qualificação dos activos, será um dos factores a explicar o escasso recurso a estas instituições.

Nas relações entre IC\&T e empresas identificam-se os mesmo problemas que tradicionalmente têm sido associados às relações universidade-indústria: diferenças de expectativas, de percepções do tempo, de percepção dos objectivos das tarefas e finalidades (Rothwell 1985; Senker, 1996; Stankiewicz, 1986; David; Foray; Steinmuller, 1998). Não se encontram porém as dificuldades de linguagem recorrentemente identificadas, a não ser que estas sejam consideradas na sua dimensão simbólica: o que estará em causa são diferenças de praxis, que limitam a compreensão das idiossincrasias de cada tipo de instituição.

Um dos resultados considerados relevantes na investigação realizada prende-se com a associação encontrada entre a existência de colaboradores das empresas com formação em áreas académicas específicas e o comportamento destas em termos de competitividade, inovação e desenvolvimento de actividades de I\&D. Um dos resultados de uma investigação realizada sobre a mobilidade dos quadros superiores em empresas portuguesas (Oliveira, 1994), permitiu concluir que a atitude face à mudança e os factores que são geradores de satisfação são diferentes em função da área de formação dos inquiridos (em função de serem economistas, engenheiros ou gestores). Coloca-se por isso a hipótese da área de formação académica se encontrar associada a diferentes posturas nas organizações, quer quanto às recompensas que delas se obtêm, quer quanto ao posicionamento estratégico destas instituições. O facto de existirem formações diversificadas nas organizações poderá igualmente expressar as vantagens que a existência de conhecimento transdisciplinar (Gibbons, et al 1997) pode implicar para as organizações.

Um último apontamento prende-se com a adequação dos indicadores de medida de actividades de I\&D em realidades como a portuguesa: atendendo à escassez de estruturas formais e orçamentos de I\&D próprios, o investimento que as empresas realizam neste tipo de actividades será analisado de forma mais fidedigna através de indicadores que abarquem a diversidade de práticas possíveis relacionadas com o desenvolvimento de produtos e processos. 


\begin{tabular}{|l|c|}
\hline \multicolumn{1}{|c|}{ I NSTI TUTOS APOI ADOS PELO CI ENCIA } & Pólos \\
\hline INESC - Instituto de Engenharia de Sistemas e Computadores & Coimbra \\
IT - Instituto de Telecomunicações & Porto \\
& $\begin{array}{c}\text { Lisboa } \\
\text { Coimbra }\end{array}$ \\
ISR- Instituto de Sistemas e Robótica & Lisboa \\
& Coimbra \\
& Porto \\
IDMEC - Instituto de Engenharia Mecânica para a Produção e Energia & Porto \\
ICEMS - Instituto de Ciência e Engenharia de Materiais e Superfícies & Coimbra \\
IBQF - Instituto de Biotecnologia e Química Fina & Lisboa \\
& Braga \\
ITQB- Instituto de Tecnologia Química e Biológica & Lisboa \\
IMAR - Instituto do Mar & Lisboa \\
& Coimbra \\
\hline
\end{tabular}




\begin{tabular}{|c|c|}
\hline I NSTI TUI ÇÕES APOI ADAS PELO PEDI P & DELEGAÇÕES \\
\hline $\begin{array}{l}\text { CATIM - Centro de Apoio Tecnológico à Indústria Metalomecânica } \\
\text { CITEVE - Centro da Indústria Têxtil e Vestuário } \\
\text { CTCV- Centro Tecnológico da Cerâmica e do Vidro } \\
\text { CENTIMFE - Centro Tecnológico da Indústria de Moldes e Ferramentas } \\
\text { Especiais } \\
\text { RAIZ- Instituto de Investigação da Floresta e Papel } \\
\text { IBET - Instituto de Biologia Experimental e Tecnológica } \\
\text { ICAT - Instituto de Ciência Aplicada e Tecnologia } \\
\text { ICTPOL - Instituto de Ciência e Tecnologia dos Polímeros } \\
\text { IDIT - Instituto de Desenvolvimento e Inovação Tecnológica } \\
\text { INEGI - Instituto de Engenharia Mecânica e Gestão Industrial } \\
\text { ITEC - Instituto Tecnológico para a Europa Comunitária/INTELI } \\
\text { ITIME - Instituto de Tecnologia e Inovação para a Modernização Empresarial } \\
\text { IPN - Instituto Pedro Nunes } \\
\text { ISQ - Instituto de Soldadura e Qualidade } \\
\text { NOVOTECNA - Associação para o Desenvolvimento Tecnológico } \\
\text { AEMITEQ - Associação para a Inovação Tecnológica e Qualidade } \\
\text { IDITE - Instituto de Desenvolvimento e Inovação Tecnológica do Minho }\end{array}$ & Lisboa \\
\hline
\end{tabular}




\section{EMPRESAS I NQUI RI DAS}

FITLENE - TEXTÊIS ARTIFICIAIS

LUSOTUFO

PT

LINK

TECNITROM

RAR

SISTEL

LEVER

TEKELEC - COMPENENTES E EQUIPAMENTOS

FACMIL

SONAFI

VULCANO

TEKA

CIPAN

METALECEIA

ARSOPI

PORTUCEL INDUSTRI AL

CELBI

MANUTENÇÃO E INTEGRIDADE

CABELTE

COVINA

EFACEC - Sistemas de Electrónica

IBEROMOLDES

PT Inovação

RINAVE

EID-.EMPRESA DE INVESTIGAÇÃO E DESENVOLVIMENTO ELECTRO SETÚBAL

GALUCHO

LAMEI RINHO

MAPRIL

OGMA

VISTA ALEGRE 


\section{REFERÊNCIAS BI BLI OGRÁfICAS}

AMABLE, B.; BARRÉ, R.; BOYER, R. (1997) Les Systèmes d'Innovation à l'Ère de la Globalisation, Paris, Economica.

ARCHIBUGI, D.; MICHIE, J. (1997) Technology, Globalization and Economic performance, Cambridge, Cambridge University Press.

AUTIO, E.; LAAMANEM; T. (1993) Technology transfer between research laboratories and industry Measurement and evaluation , Espoo, Technical Research Centre of Finland.

AUTIO, E.; LAAMANEM; T. (1995) "Measurement and evaluation of technology transfer: review of technology transfer mecahnisms and indicators” Int. J. Technology Management Vol. 10, No 7/8 pp. 643664.

BARATA, José (1999) "Inovação na indústria transformadora portuguesa: alguns resultados de inquérito recente” in Manuel Mira Godinho, e João Caraça (org) O Futuro Tecnológico Oeiras, Celta.

BELL, Martin; PAVITT, Keith (1997) “ Technological accumulation and industrial growth: contrasts between developed and developing countries" in Daniele Archibugi e John Michie Technology, Globalization and Economic Performance, Cambridge, Cambridge University Press.

BESSANT, John; RUSH, Howard (1996) "Building bridges for innovation: the role of consultants in technology transfer” Research Policy 24 pp. 97-114.

CALLON, Michel (1992) “The dynamics of techno-economic networks" in Rod Coombs; Pier P. Saviotti e Vivien Walsh Technological Change and Company Strategies, Londres, Academic Press.

CALLON, Michel; LAREDO, Philippe; MUSTAR, Pierre (1995) "Les réseaux technico-economiques et l'analyse des effets structuraux" in Michel Callon, Philippe Larédo, e Pierre Mustar (org.) The Strategic Management of Research and Technology Paris, Economica.

CARAÇA, João (1999) “Ciência e mudança: duas características indissociáveis do século XX” in Manuel Mira Godinho, e João Caraça (org) O Futuro Tecnológico Oeiras, Celta.

CASTRO, F.B.; BUCKLEY, J. (2001) Foreign Direct Investement and the Competitiveness of Portugal in Como Está a Economia Portuguesa? Livro de Actas, Lisboa, CISEP.

COHEN, W.M.; LEVINTHAL , D.A. (1989) "Innovation and learning: the two faces of R\&D" The Economic Journal 99 (sep.).

COOKE, Phillip; MORGAN, Kevin (1994) "The creative milieu: a regional perspective on innovation" in Mark Dodgson e Roy Rothwell The Handbook of Industrial Innovation, Londres, Edward Elgar.

DAVID, Paul; FORAY, Dominique; STEINMULLER, Edward (1998) "The research network and the new economics of science: from metaphors to organizational behaviours” in Aurora Gambardella e Franco Malerba, The Organization of Innovative Activities in Europe, Cambridge, Cambridge University Press.

EC (1994) The Future of Research and Technology Organizations in Europe, Luxemburgo.

EC (2000) Science, Technology and Innovation - Key Figures 2000, Bruxelas, EC.

EC (2001) Towards a European Research Area - Key Figures 2001, Bruxelas, EC.

EDQUIST, C. (org.) (1997) Systems of innovation , London, Pinter Publishers. 
FREEMAN, C.; SOETE, L.; (1997) The Economics of Industrial Innovation, London, Pinter Publisher.

FURTADO, A.; FERMISSON, J. (2001) "Evolução do Perfil Industrial das Regiões Portuguesas no período 1982-1998: Diversidade, Tendências e Implicações” Como Está a Economia Portuguesa? Livro de Actas, Lisboa, CISEP.

GIBBONS, M; JOHNSTON, R. (1974) “The roles of science in technological innovation” Research Policy 3, pp. 220-242.

GIBBONS, Michael et alli (1997) The New Production of Knowledge, Londres, Sage.

GODINHO, Manuel Mira (2000) “Os Recursos Humanos em C\&T: Evidência de uma Fragilidade Estrutural”, Sociedade e Trabalho, $n^{\circ}$ 9, Junho 2000.

GODINHO, Manuel Mira et alli (1997) "S\&T Policies in Portugal and the Promotion of Endogenous Capabilities: the Case of Technology Infrastructure Investment, International Conference: Technology Policy and Less Developed Research and Development Systems in Europe, Sevilha.

GODINHO, Manuel Mira; MAMEDE, Ricardo Paes, (2001) "Evolução da produtividade, Mudança Estrutural e Convergência Económica nos ‘Países da Coesão’ da UE” in Como Está a Economia Portuguesa? Livro de Actas, Lisboa, CISEP.

HADJI, Charles (1994) A Avaliação, regras do Jogo, Porto, Porto Editora.

HILL, Andrew e HILL, Manuela (2000) “ A definição da amostra e os indicadores utilizados” in

Competitividade e Exclusão Social, as Áreas Metropolitanas de Lisboa e Porto - Relatório Final.

HOFSTEDE, Geert (1997) Culturas e Organizações, Lisboa, Edições Sílabo.

HOWELLS, J. (1996) “Tacit knowledge, innovation and technology transfer” Technology Analysis \& Strategic Management 8(2) pp. 91-106.

KIM, Linsu, NELSON, Richard (2000) Technology Learning and Innovation - Experiences of Newly Industrializing Economies, Cambridge, Cambridge University Press.

LARANJA, M.; SIMÕES., V.C.; FONTES, M. (1997) Inovação tecnológica - Experiências das Empresas Portuguesas, Lisboa, Texto Editora.

LISTART (1999) Innovation Support Needs of Industrial and Services Firms in Lisbon and the Tagus Valley, Lisboa.

LUNDVALL, Bengt-Ake (1992) National Systems of Innovation: towards a theory of innovation and interactive learning, London, Pinter Publishers.

LUNDVALL, Bengt-Ake, BORRÁS, Susane (1999) The Globalising Learning Economy: Implications for Innovation Policy, DGXII.

LUNDVALL, Johnson, Andersen, Dalum, 2001"National Systems of Production, Innovation and Competence Building” DRUID Working Paper, Aalborg.

NELSON, R. (1993) National Innovation Systems: a comparative analysis, Nova Iorque, Oxford University Press.

OCT (s.d.) “As Empresas no Sistema de I\&D em Portugal (1995-1997)” www.fct.mct.pt

OCT (1998) "Política Científica e Tecnológica - Diagnóstico e orientações de médio e de curto prazo" Documento de Trabalho, OCT-01/98 
OLIVEIRA, Teresa V. (1994) Factores Explicativos da Mobilidade de Quadros, tese de Mestrado em Políticas e Gestão de Recursos Humanos, Lisboa, ISCTE

OLIVEIRA, Teresa V. (2000) "A interacção das infra-estruturas científicas e tecnológicas e o sector produtivo - perspectivas do lado dos utilizadores" Comunicação apresentada no Workshop "Mudança socioeconómica 10 anos do DINÂMIA uma experiência interdisciplinar”, Novembro, DINÂMIA/ISCTE

OLIVEIRA, Teresa V. (2002) "The intervention context of the S\&TI in Portugal" Comunicação apresentada na DRUID Winter 2002 PhD Conference em Aalborg, Janeiro

PAVITT, Keith (1984) "Sectoral patterns of technical change - towards a taxonomy and a theory" Research Policy 13 (6) pp. 343-373.

RUIVO, Beatriz (1998) As Políticas de Ciência e Tecnologia e o Sistema de Investigação, Lisboa, INCM.

RUSH, Howard et alli (1996) Technology Institutes: Strategies for Best Practice, Londres, Thomson Business Press.

SALAVISA, Isabel (2000) "Especialização Internacional e Competitividade em Portugal (1970-1996) in Isabel SALAVISA (org.) A Indústria Portuguesa - Especialização Internacional e Competitividade, Oeiras, Celta.

SECT (1995) Guia de I\&D em Portugal, Lisboa, MPAT.

SIMÕES, V., C. (1997) Inovação e Gestão em PME Lisboa GEPE.

SOETE, Luc (2000) A Economia Baseada no Conhecimento num Mundo Globalizado” AAVV Para uma Europa da Inovação e do Conhecimento, Lisboa, Celta. 